\title{
On the suitability of current atmospheric reanalyses for regional warming studies over China
}

\section{Chunlüe Zhou et al.}

Correspondence to: Kaicun Wang (kcwang@bnu.edu.cn)

The copyright of individual parts of the supplement might differ from the CC BY 4.0 License. 
NWP reanalysis
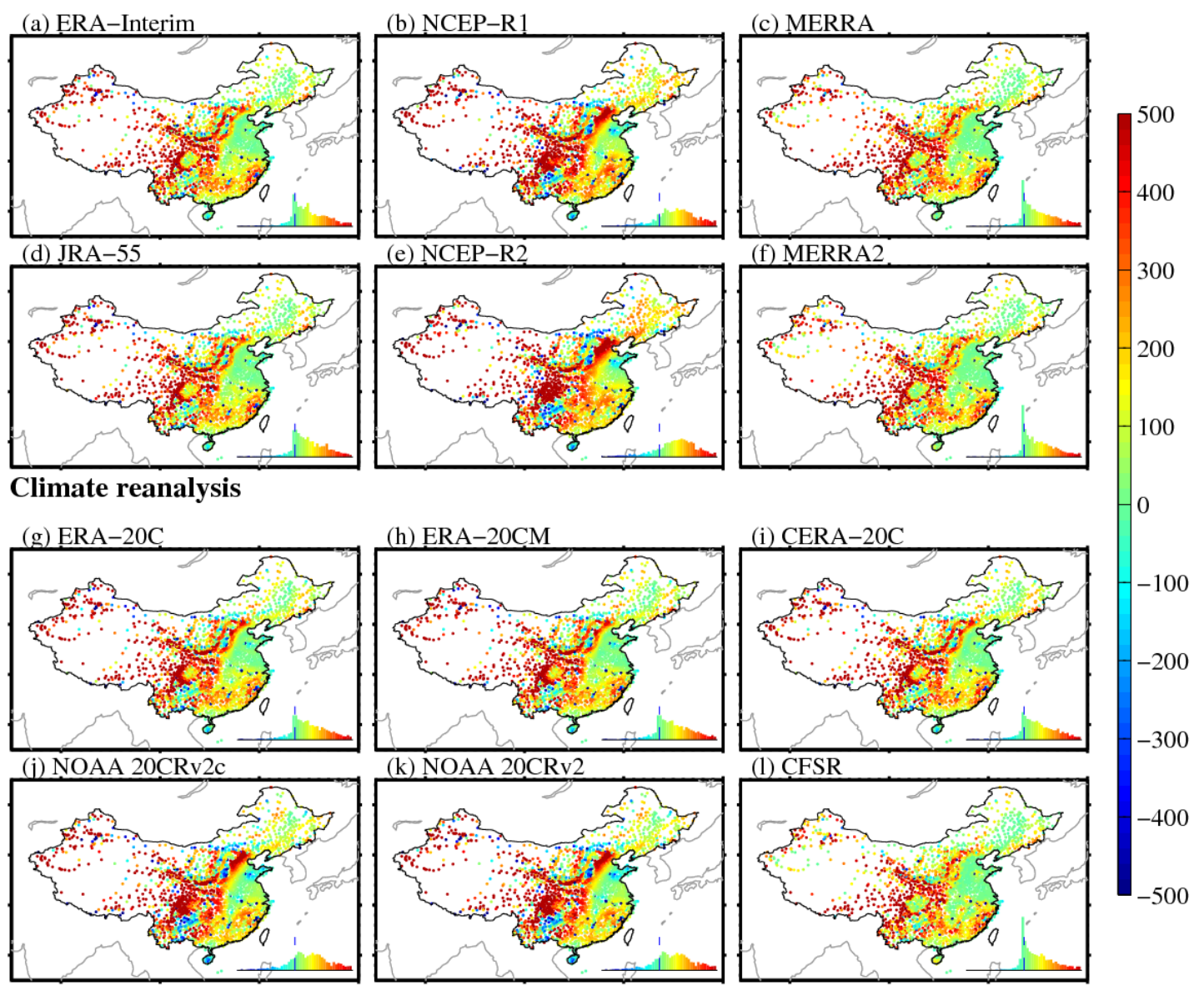

Figure S1. The elevation difference ( $\Delta$ Height, unit: $\mathrm{m})$ between the model and observation stations. The information on model resolution is included in Table 1 . 


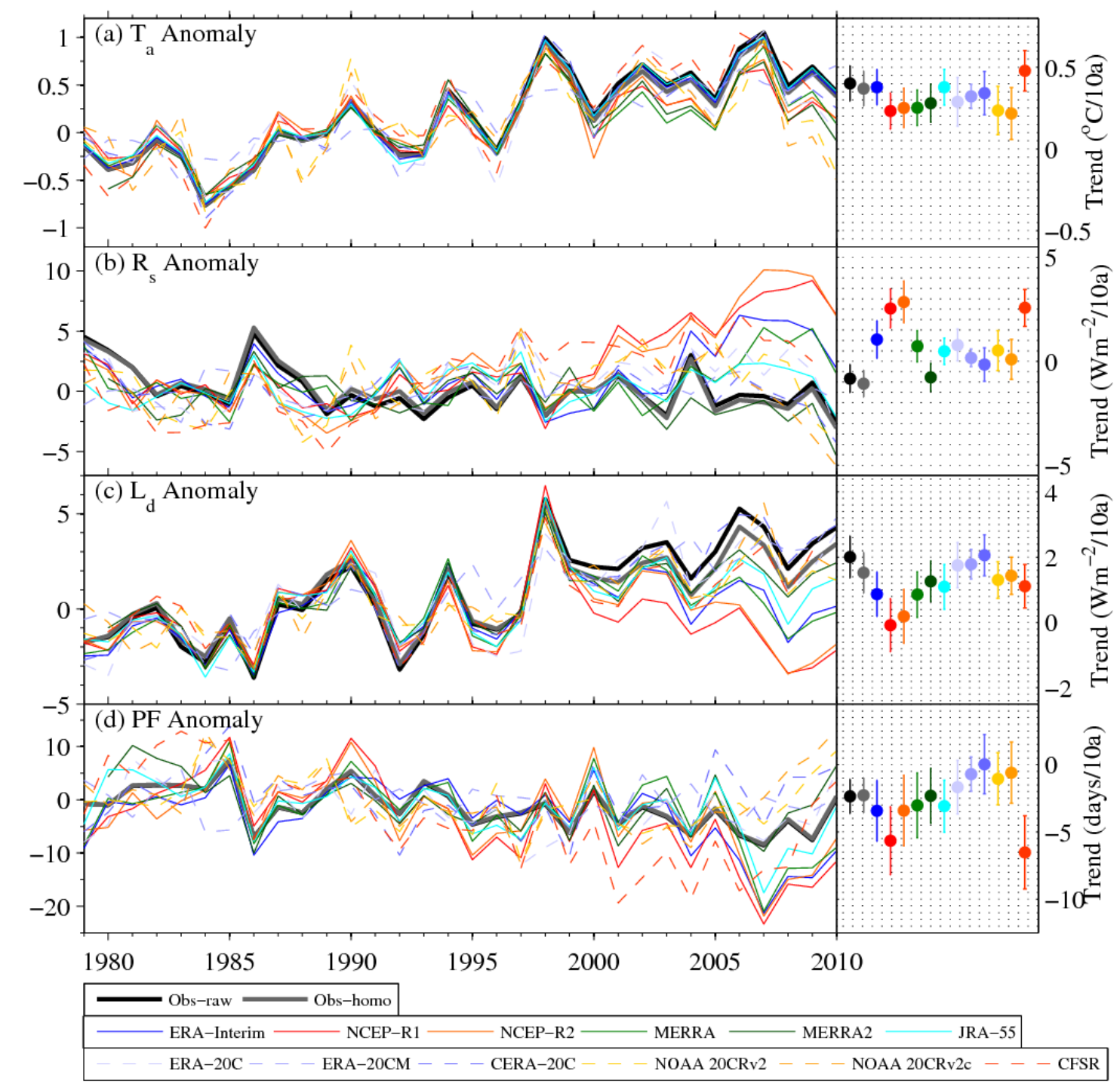

Figure S2. The time series of (a) surface air temperature anomaly $\left(T_{a}\right)$, (b) surface incident solar radiation $\left(R_{s}\right)$, (c) surface downward longwave radiation $\left(L_{d}\right)$ and $(\mathbf{d})$ precipitation frequency anomaly (PF) with their trends (in right each) from the raw observation, homogeneous observation and the twelve reanalysis products during the period 1979-2010 over China. The error-bars show the 95\% confident intervals of the trends. 

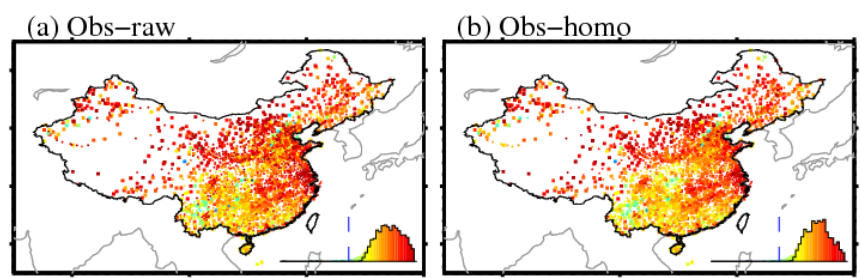

NWP reanalysis
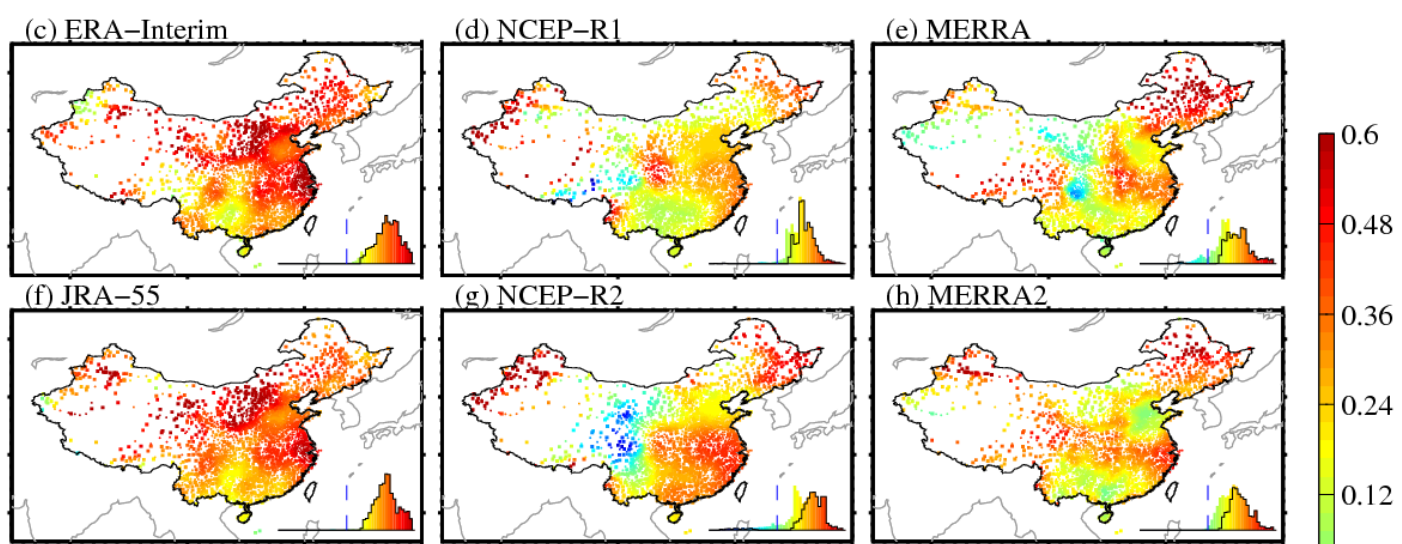

Climate reanalysis
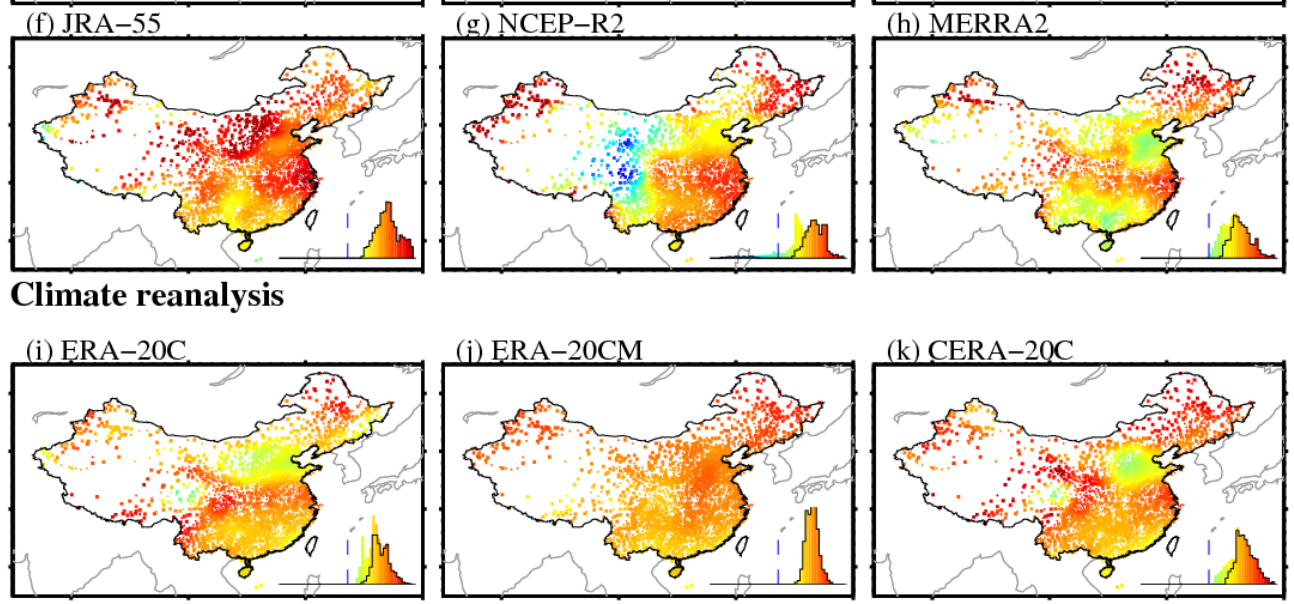

0.36

0.24

0.12
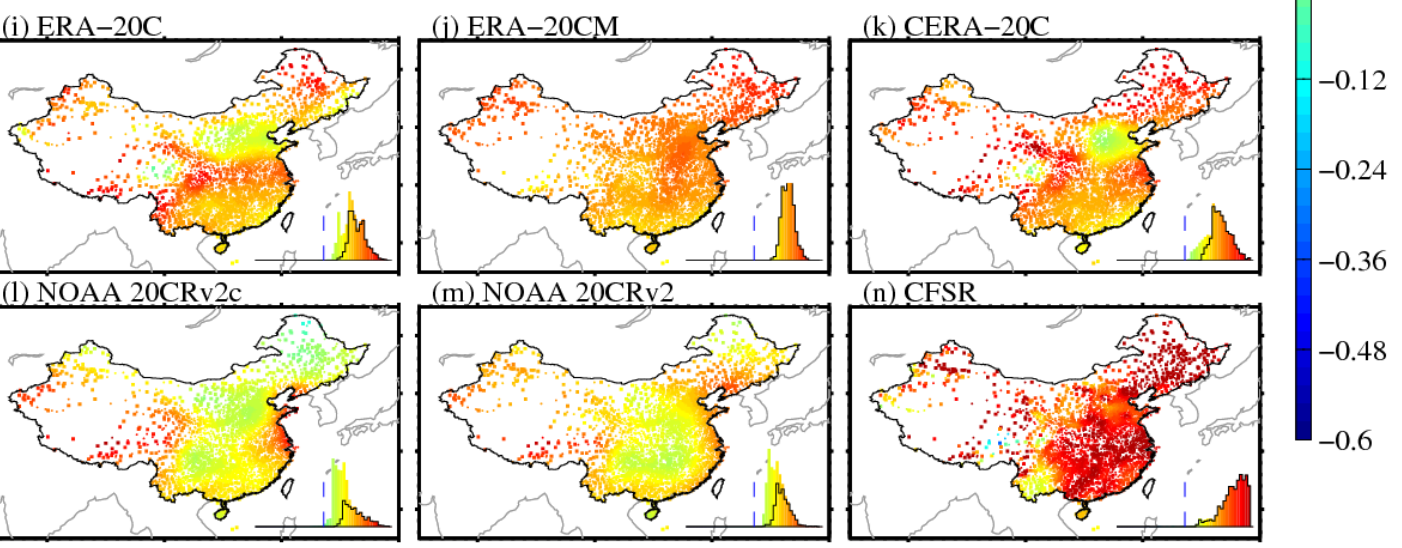

Figure S3. The trends in surface air temperature $\left(T_{a}\right.$, unit: $\left.{ }^{\circ} \mathrm{C} / \mathrm{decade}\right)$ during the period 1979-2010 from (a) raw observations, (b) homogeneous observations and the twelve reanalysis products over China, i.e., (c) ERA-Interim, (d) NCEP-R1, (e) MERRA, (f) JRA-55, (g) NCEP-R2, (h) MERRA2, (i) ERA-20C, (j) ERA-20CM, (k) CERA-20C, (l) NOAA 20CRv2c, (m) NOAA 20CRv2 and (n) CFSR. The probability distribution functions of all the trends are shown as colored histogram, and the black stairs are integrated from the trends with a significance level of 0.05 (based on two-tailed Student's $t$-test). 


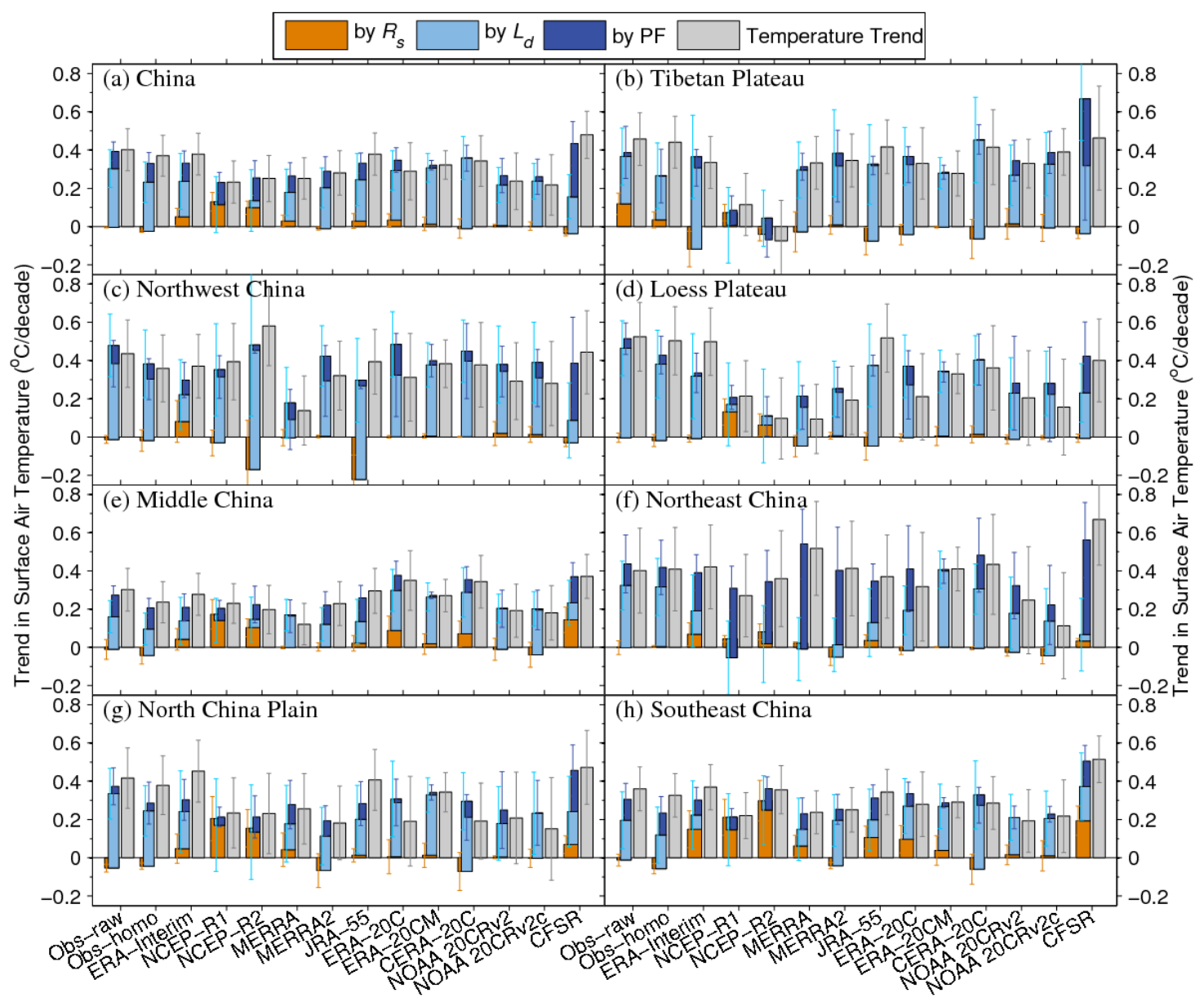

Figure S4. Contribution of trends in surface air temperature $\left(T_{a}\right.$, unit: ${ }^{\circ} \mathrm{C} / \mathrm{dec}$ ade $)$ from three relevant parameters, i.e., surface incident solar radiation $\left(R_{s}\right.$, in brown, unit: $\mathrm{W} \cdot \mathrm{m}^{-2} /$ decade), surface downward longwave radiation $\left(L_{d}\right.$, in light blue, unit: $\mathrm{W} \cdot \mathrm{m}^{-2} /$ decade) and the precipitation frequency (PF, in deep blue, unit: days/decade) during the period 1979-2010 in the raw observations, homogeneous observations and the twelve reanalysis products over China and its seven subregions. 


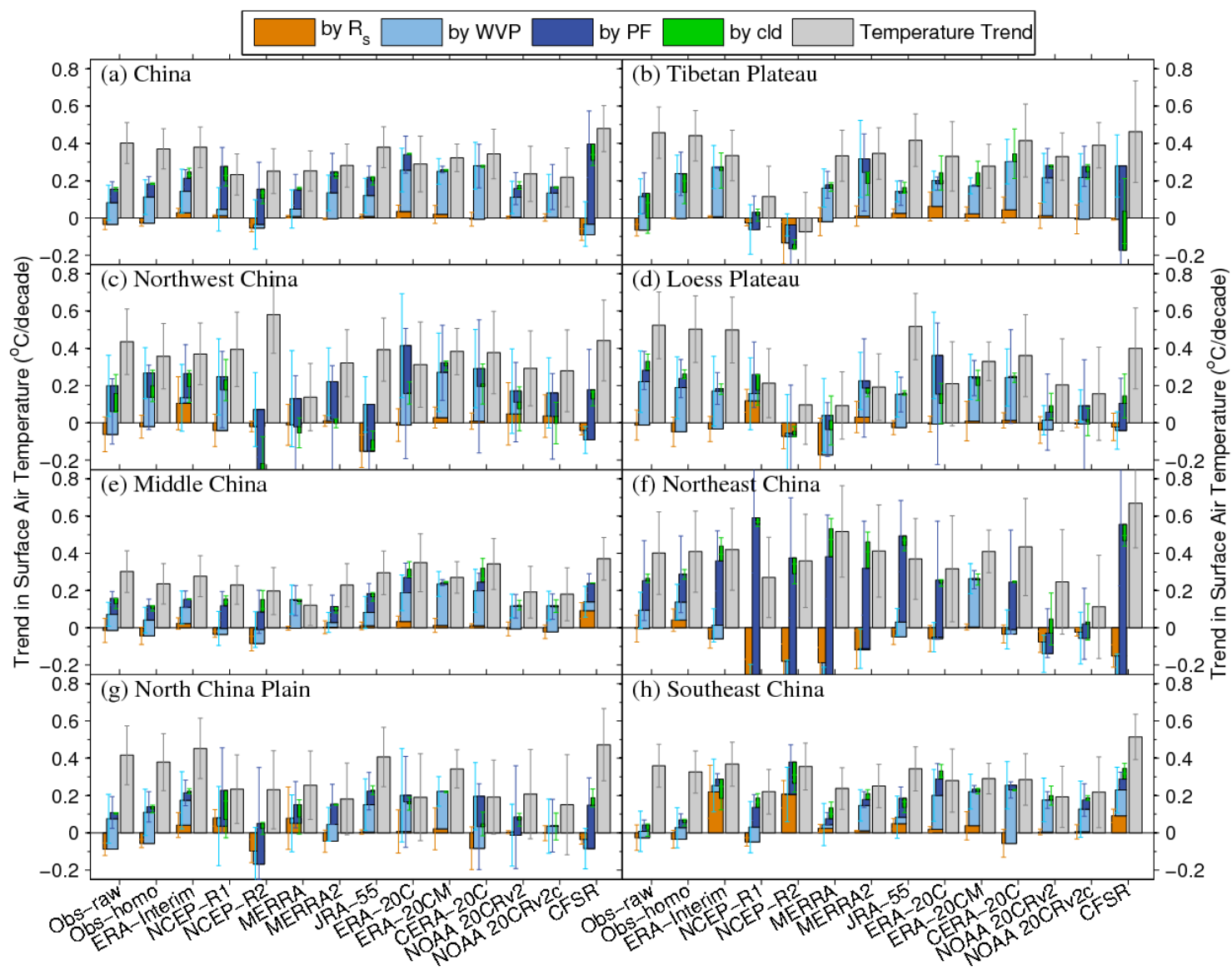

Figure S5. The same as Figure S4, but using the atmospheric water vapor and cloud

fraction instead of surface downward longwave radiation. 

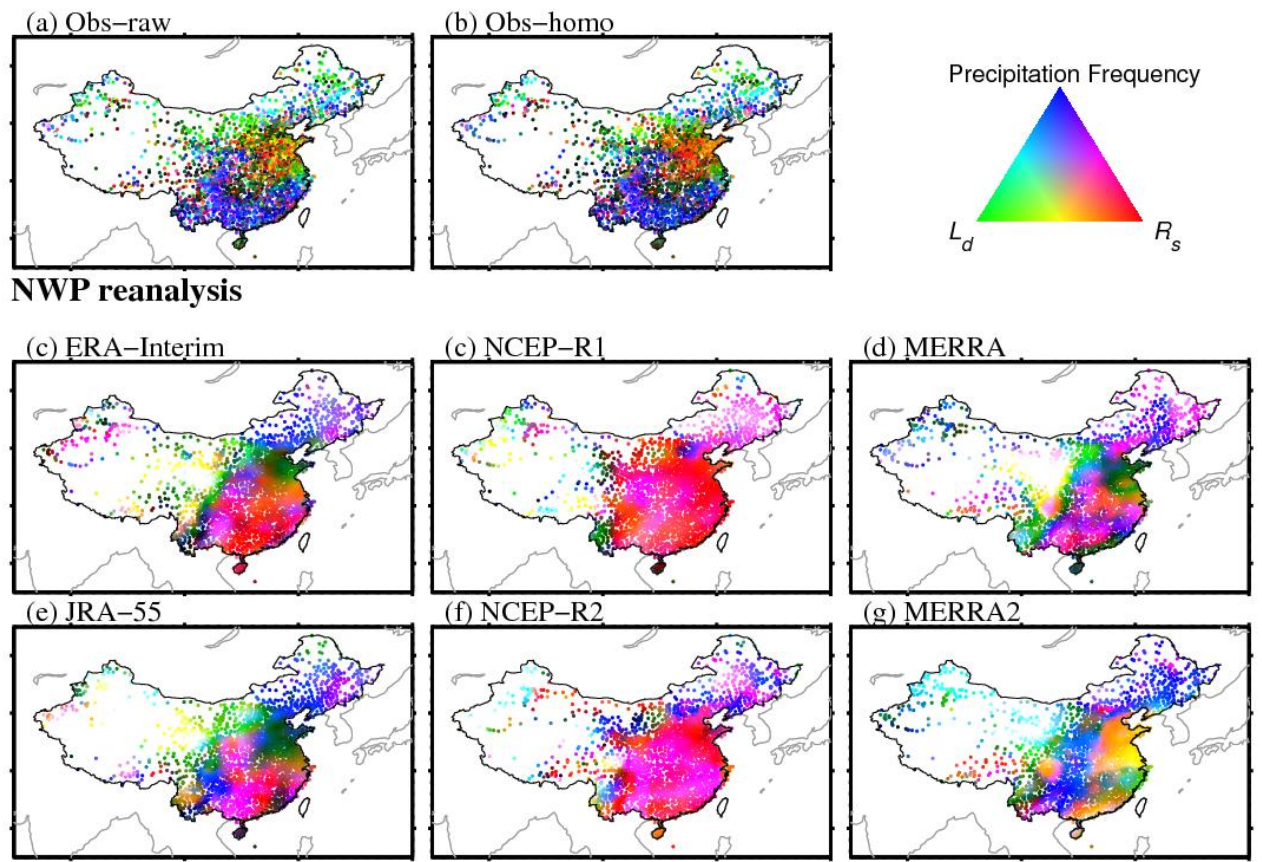

Climate reanalysis
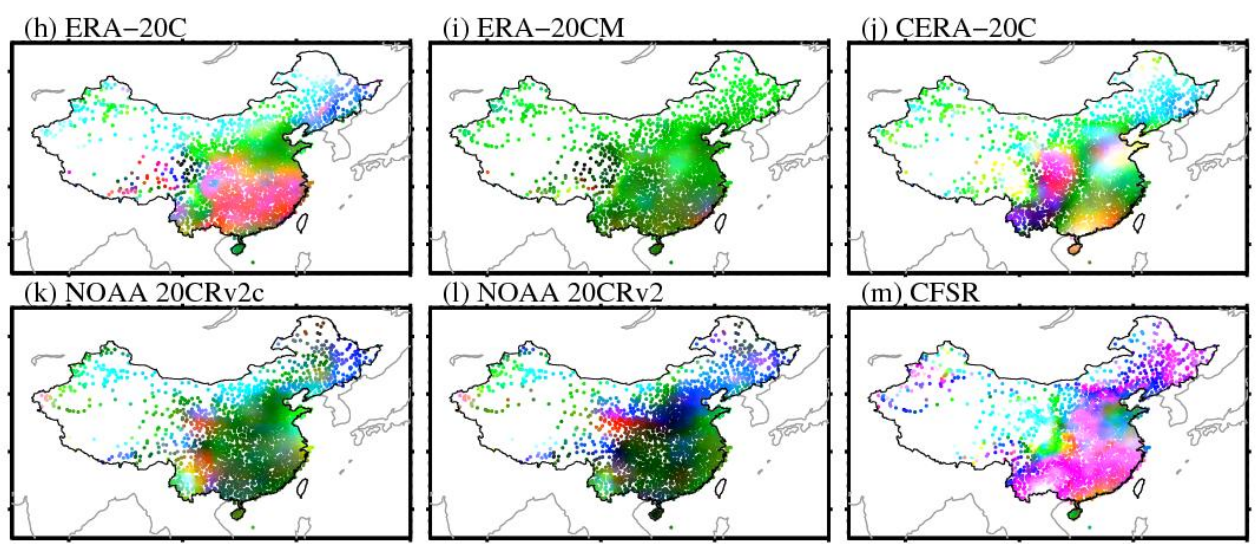

Figure S6. Composite map of contribution of trends in three relevant parameters

51 [surface incident solar radiation $\left(R_{s}\right.$, in red), surface downward longwave radiation $\left(L_{d}\right.$,

52 in green) and the precipitation frequency (in blue)] to trends in surface air temperature ( $T_{a}$, unit: ${ }^{\circ} \mathrm{C} /$ decade) during the period 1979-2010 from (a) the raw observations, (b)

54 homogeneous observations and the twelve reanalysis products over China, i.e., (c) ERA-Interim, (d) NCEP-R1, (e) MERRA, (f) JRA-55, (g) NCEP-R2, (h) MERRA2, 20CRv2 and (n) CFSR. 

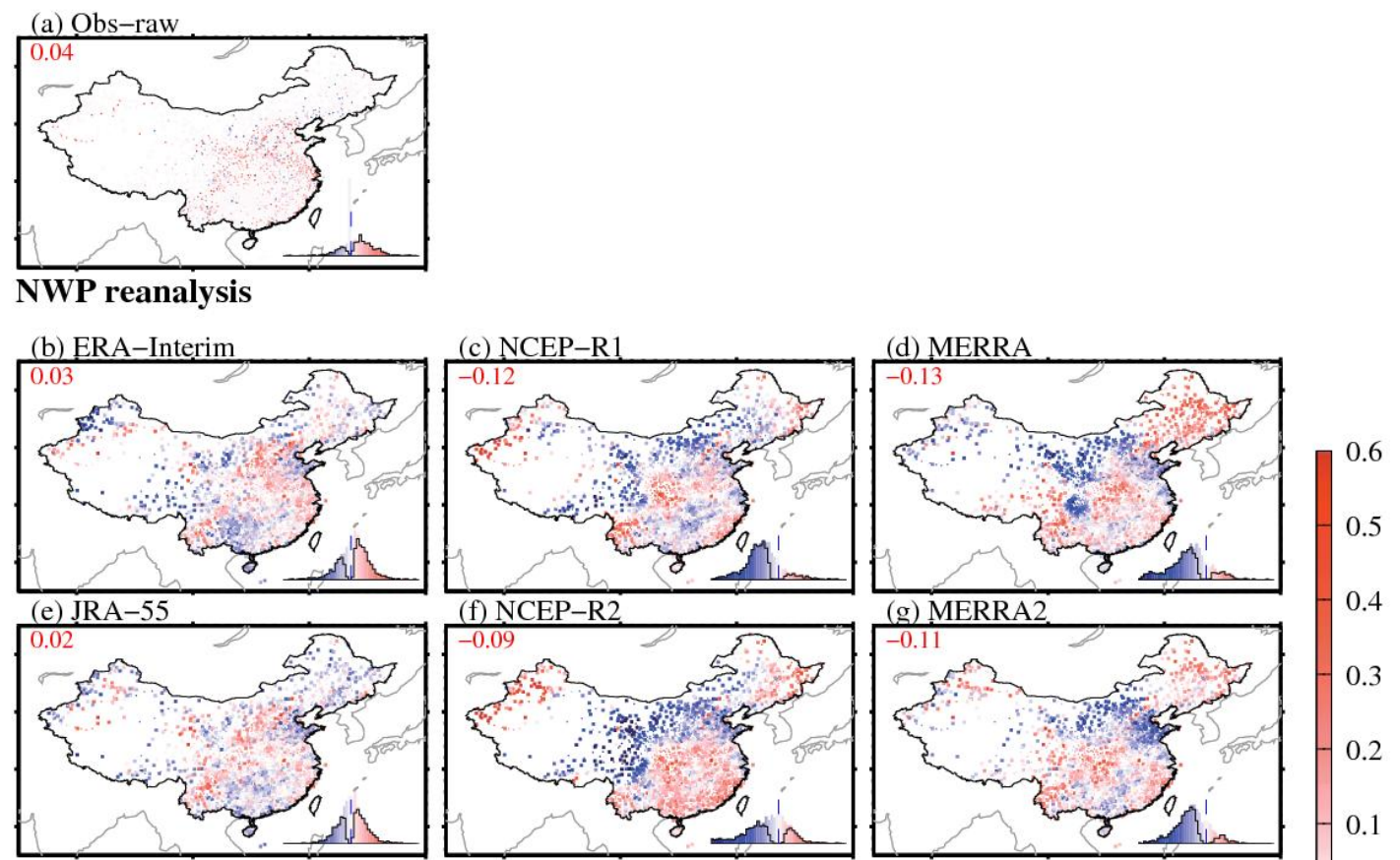

$-0.4$

Climate reanalysis
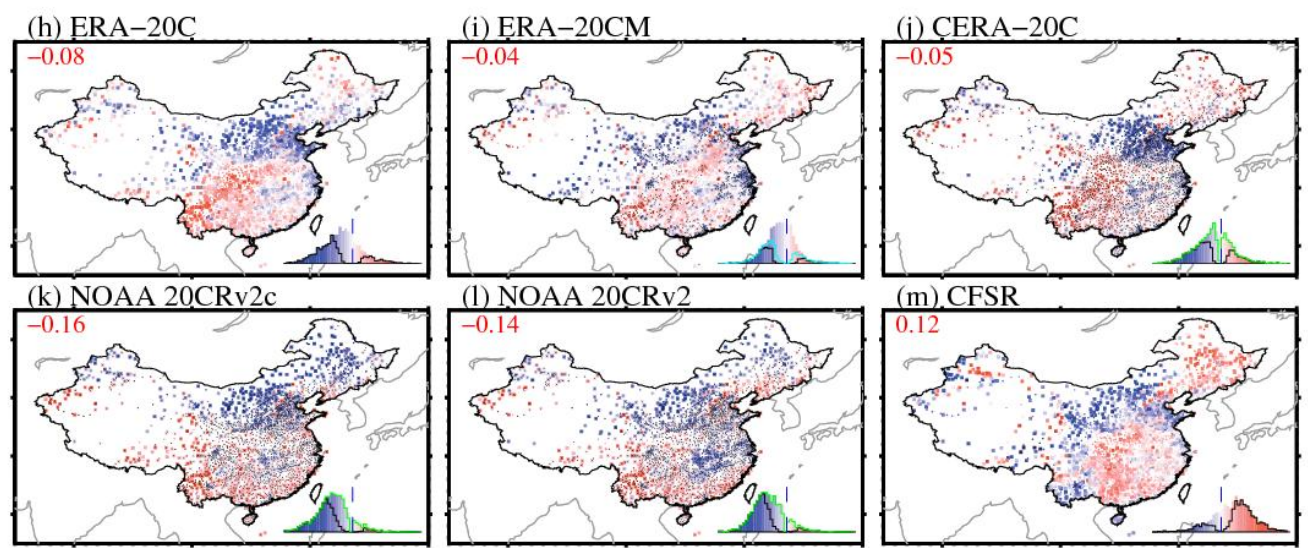

$-0.3$

Figure S7. The same as Figure 5, but the colorbar is adjusted by adding mean value

60 (in red number within each subfigure). 

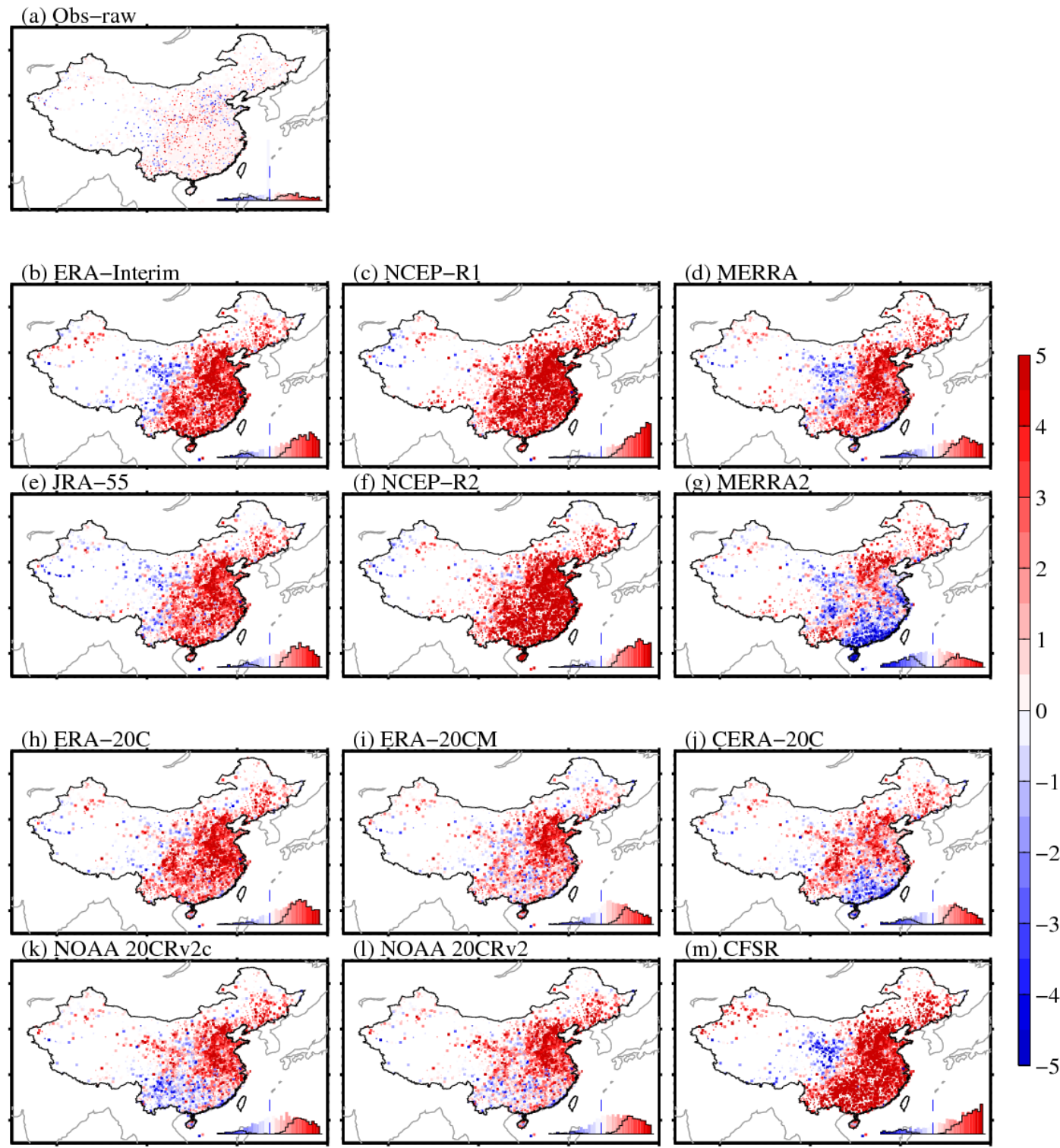

Figure S8. The simulated trend biases in surface incident solar radiation $\left(R_{s}\right.$, unit:

$\mathrm{W} \cdot \mathrm{m}^{-2} /$ decade) during the period $1979-2010$ from the observations and the twelve reanalysis products over China. The probability distribution functions of all the trends are shown as colored histogram, and the black stairs are integrated from the trends with a significance level of 0.05 (based on two-tailed Student's $t$-test). 

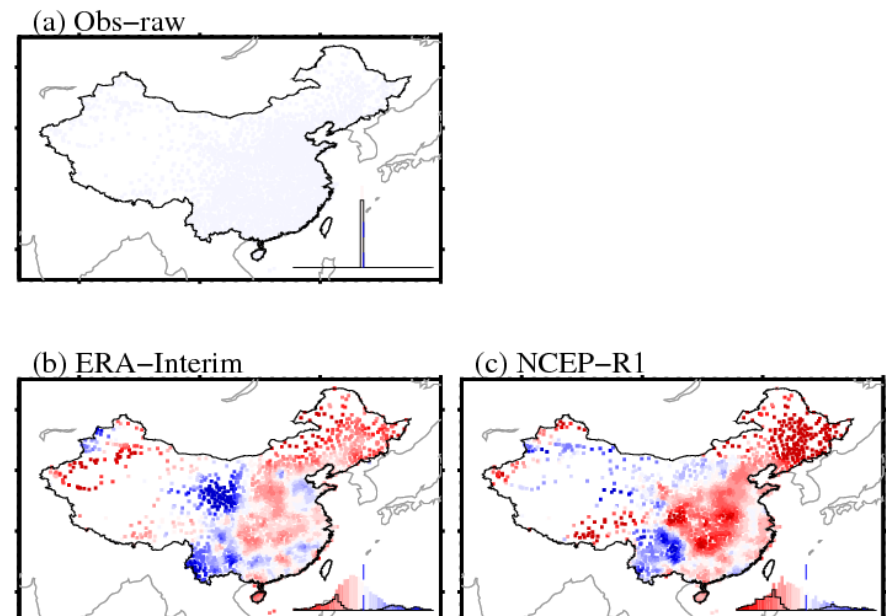

(d) MERRA
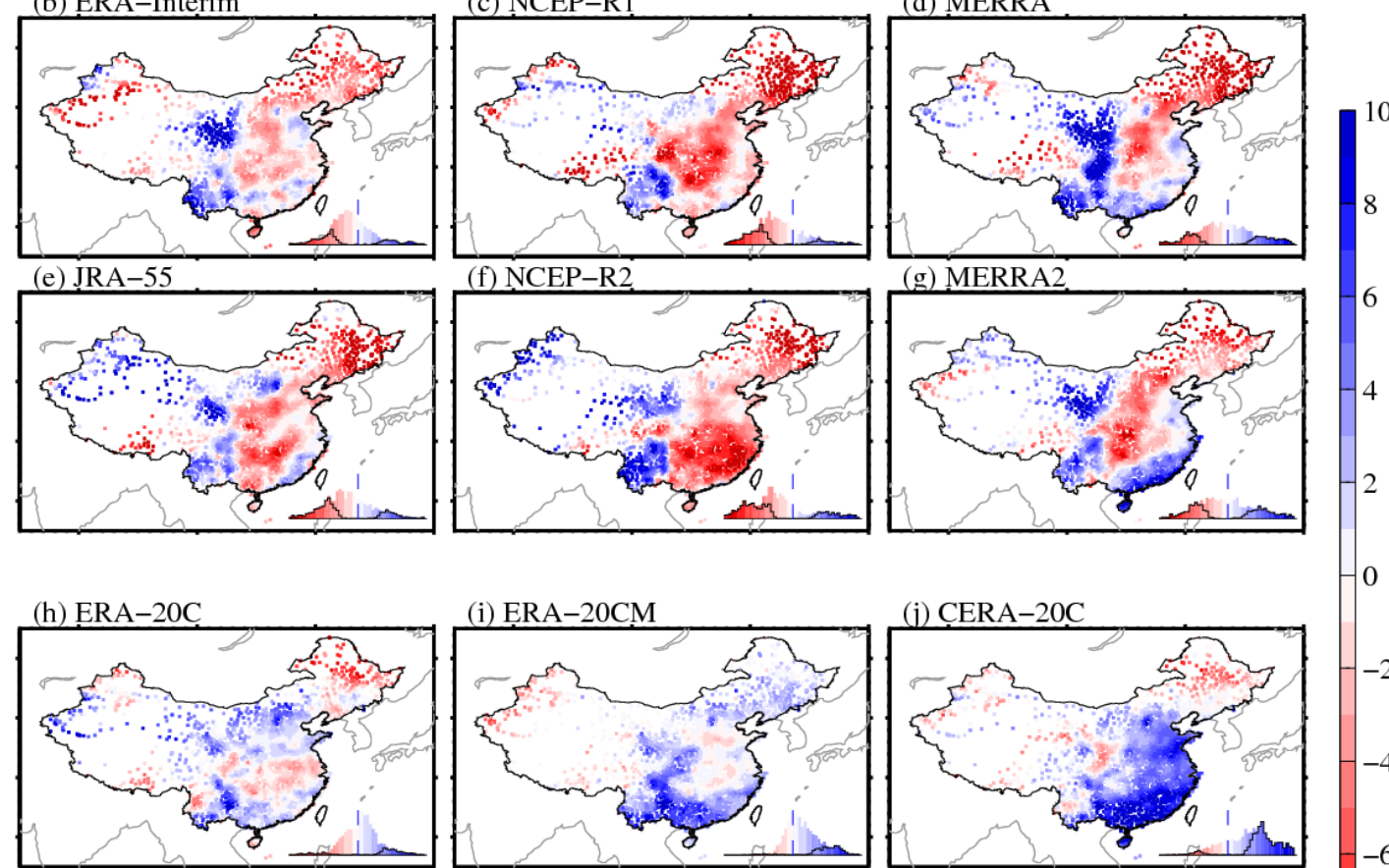

(k) NOAA 20CRv2c
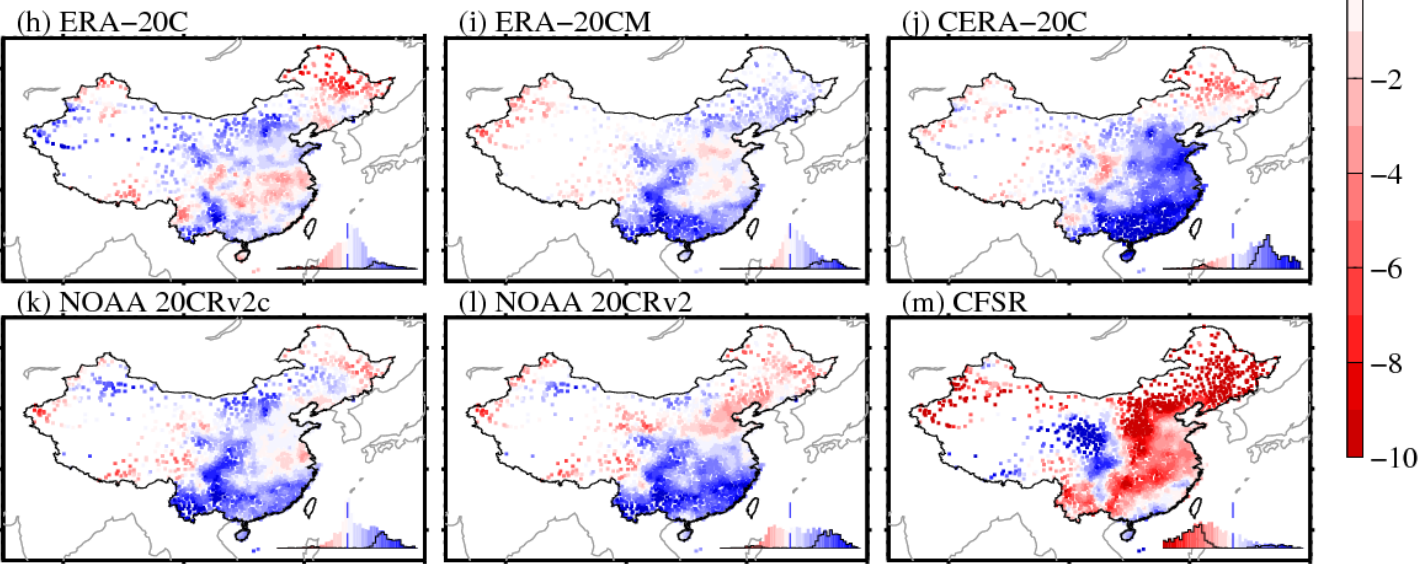

Figure S9. The simulated trend biases in the precipitation frequency (PF, unit: days/decade) during the period 1979-2010 from the observations and the twelve reanalysis products over China. The probability distribution functions of all the trends are shown as colored histogram, and the black stairs are integrated from the trends with a significance level of 0.05 (based on two-tailed Student's $t$-test). 

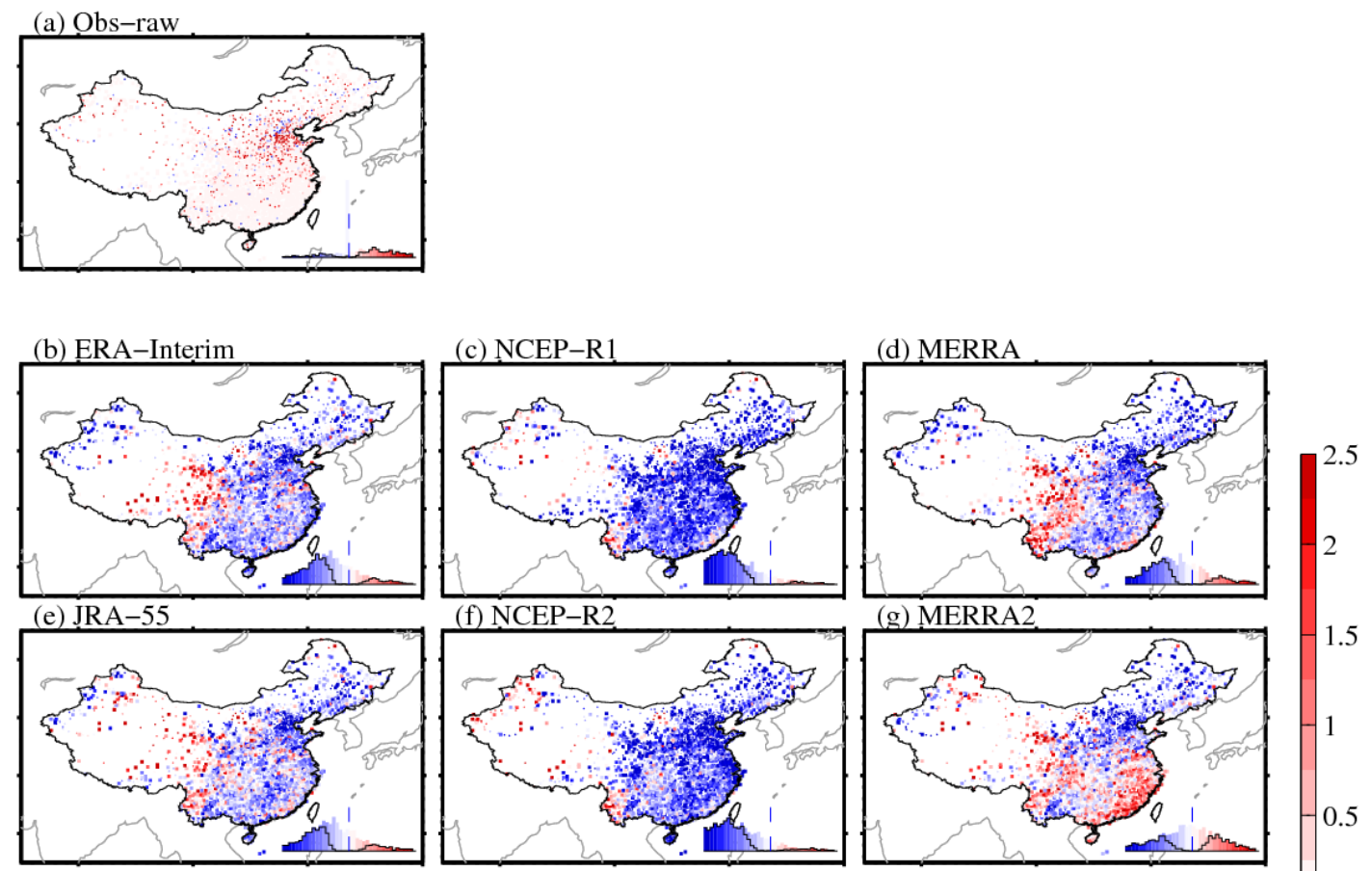

1.5
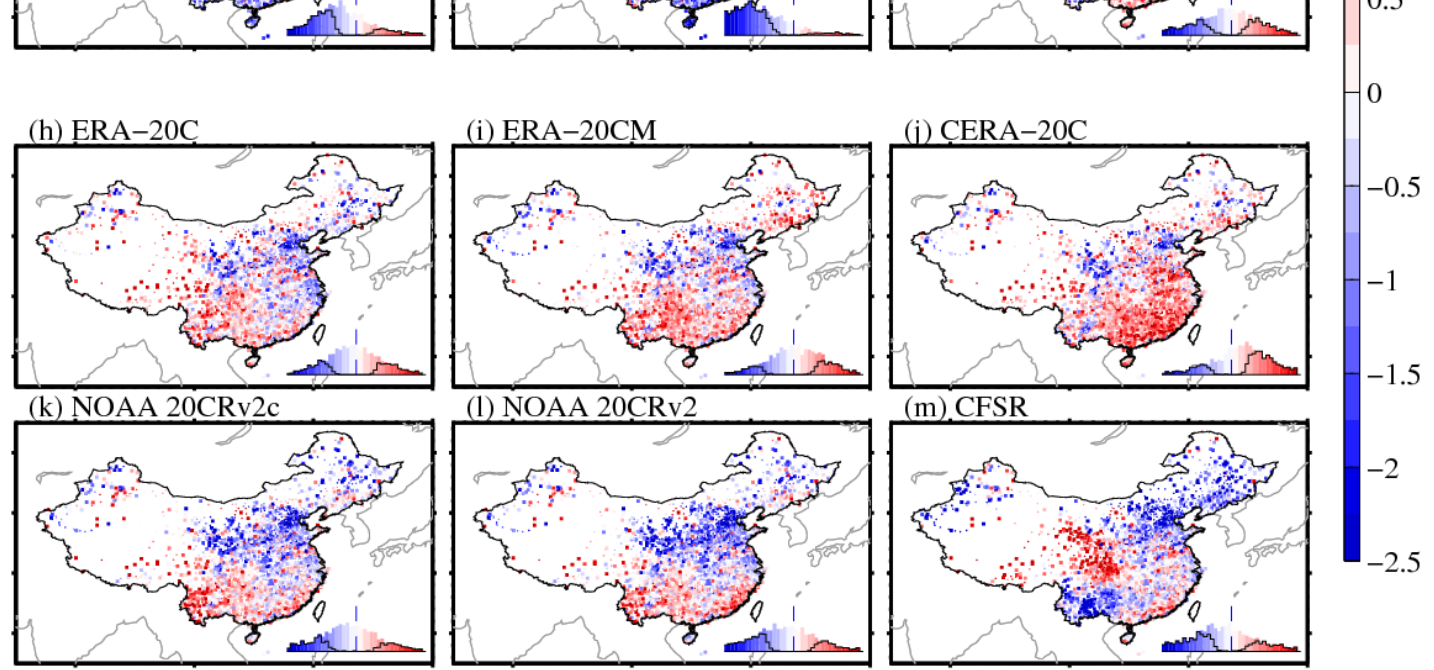

Figure S10. The simulated trend biases in surface downward longwave radiation $\left(L_{d}\right.$, unit: $\mathrm{W} \cdot \mathrm{m}^{-2} /$ decade) during the period $1979-2010$ from the observations and the twelve reanalysis products over China. The probability distribution functions of all the trends are shown as colored histogram, and the black stairs are integrated from the trends with a significance level of 0.05 (based on two-tailed Student's $t$-test). 

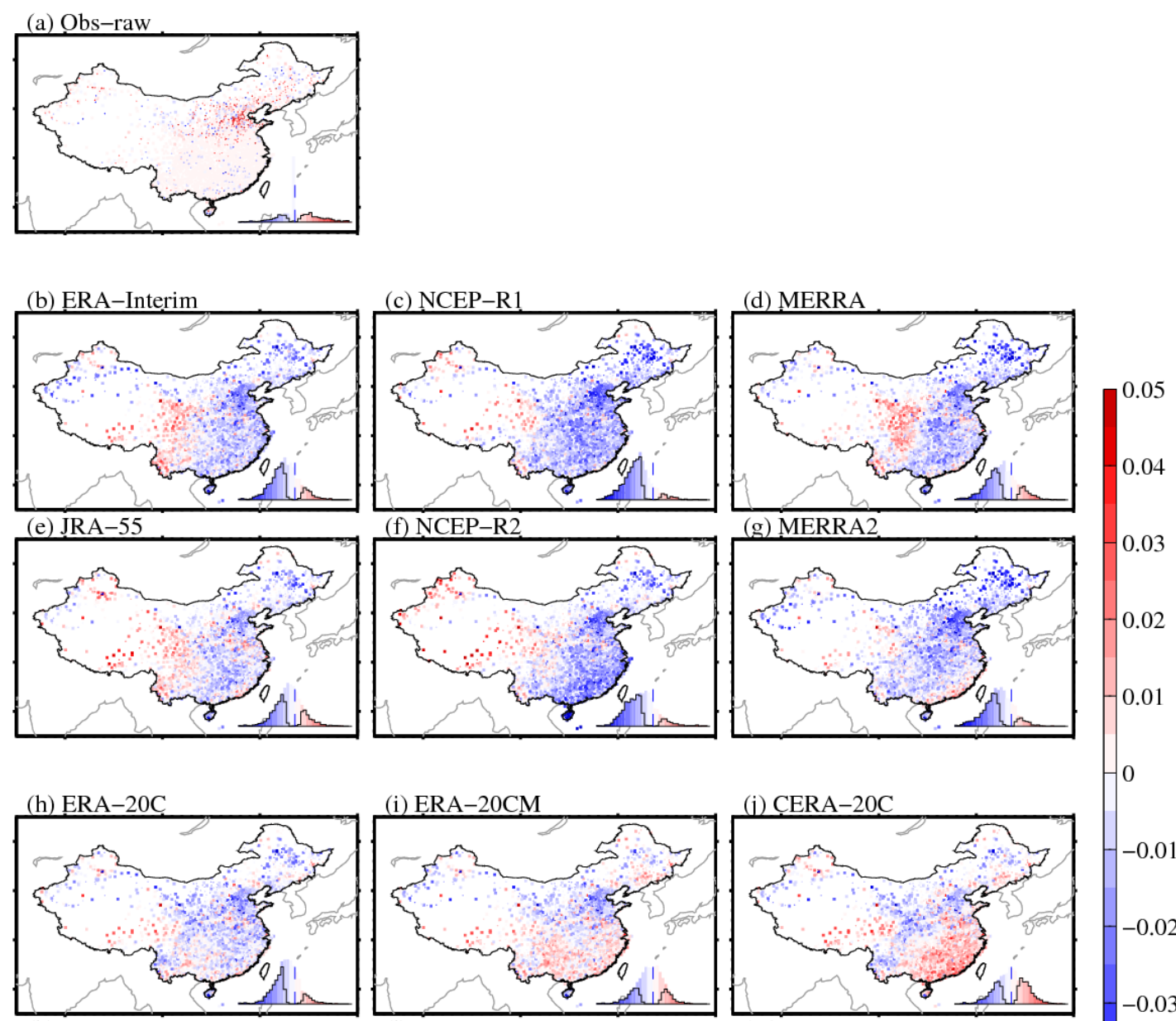

- 0

$-0.02$
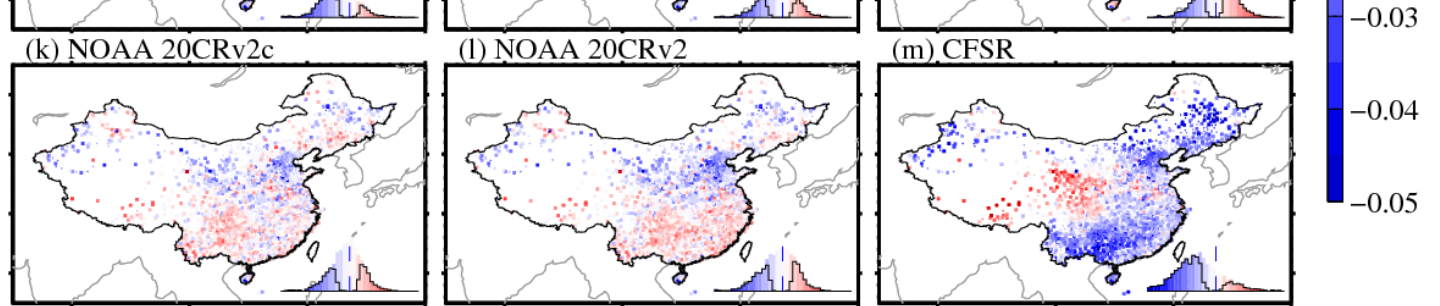

Figure S11. The simulated trend biases in cloud fraction (cld, unit: 1/decade) during the period 1979-2010 from the observations and the twelve reanalysis products over China. The probability distribution functions of all the trends are shown as colored histogram, and the black stairs are integrated from the trends with a significance level of 0.05 (based on two-tailed Student's $t$-test). 

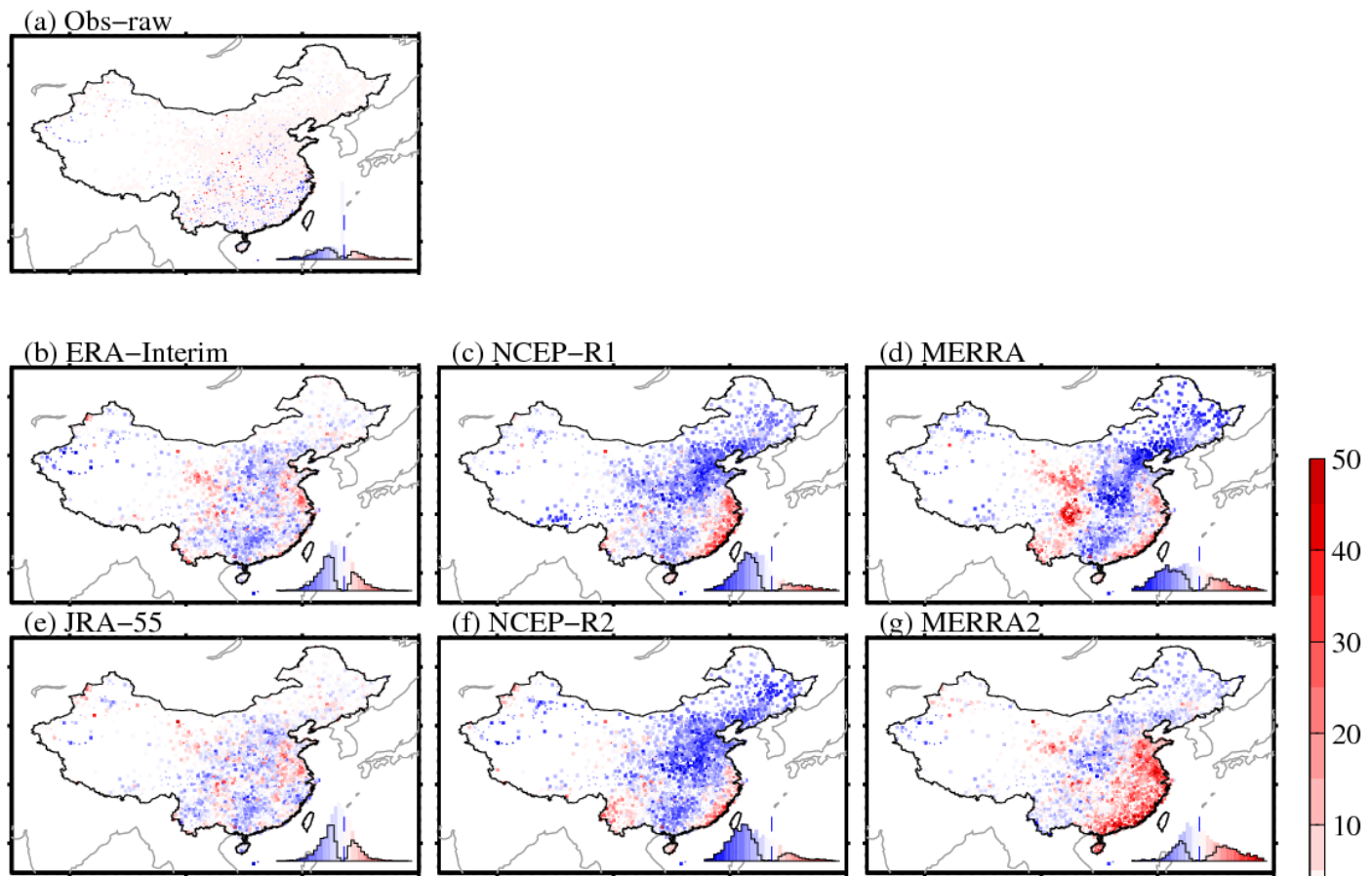

(g) MERRA2

30
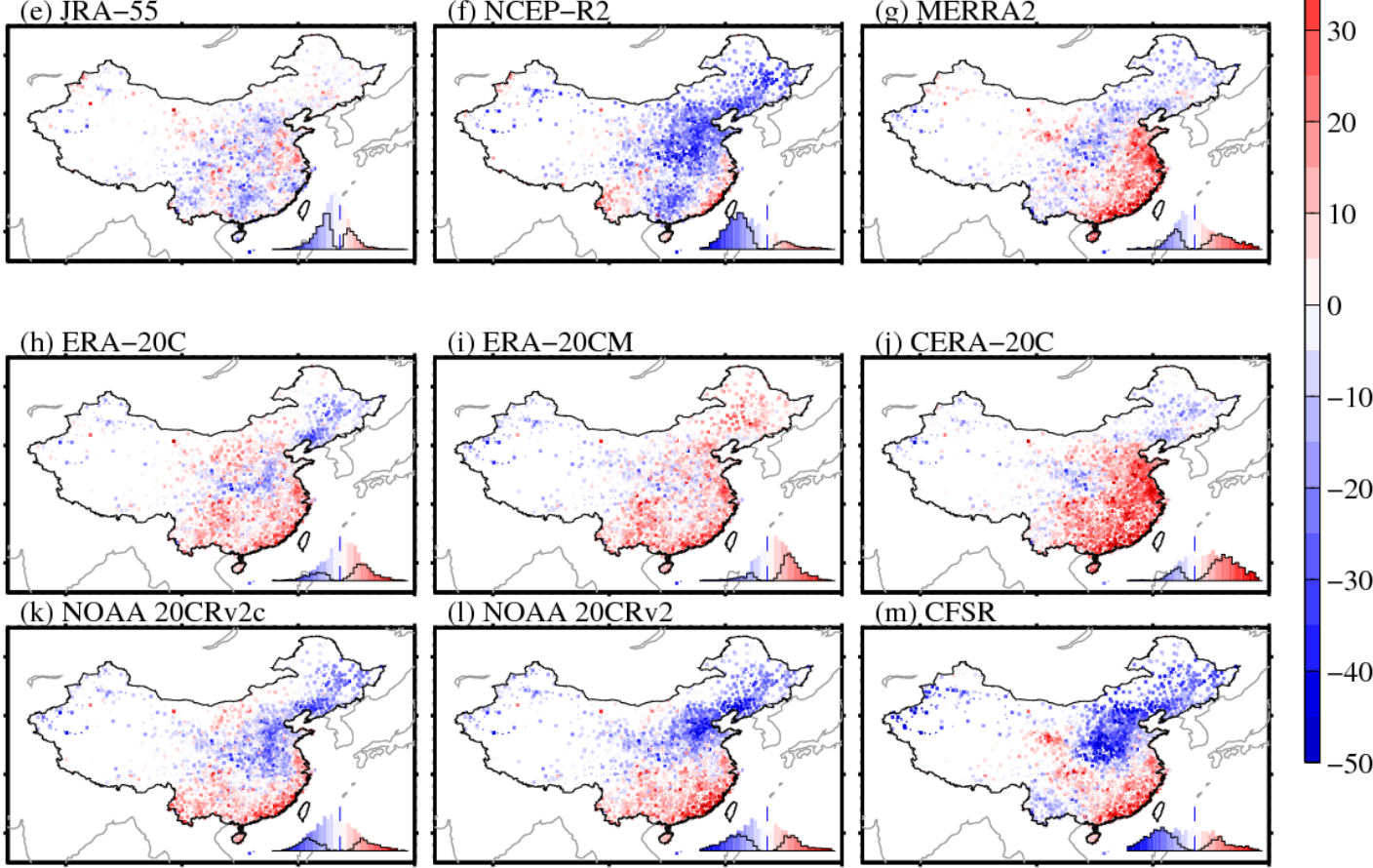

Figure S12. The simulated trend biases in the atmospheric water vapor (WVP, unit:

$\mathrm{Pa} /$ decade) during the period 1979-2010 from the observations and the twelve reanalysis products over China. The probability distribution functions of all the trends are shown as colored histogram, and the black stairs are integrated from the trends with a significance level of 0.05 (based on two-tailed Student's $t$-test). 

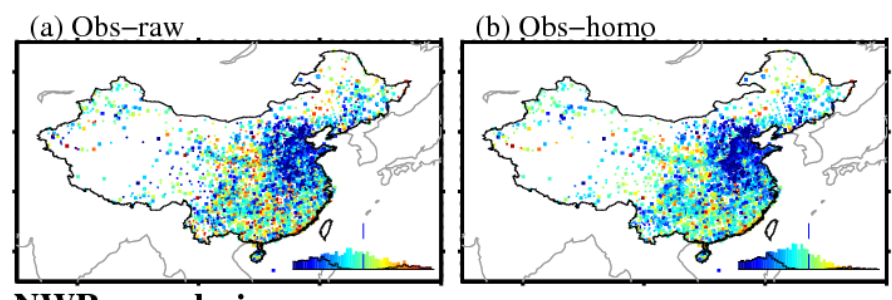

\section{NWP reanalysis}
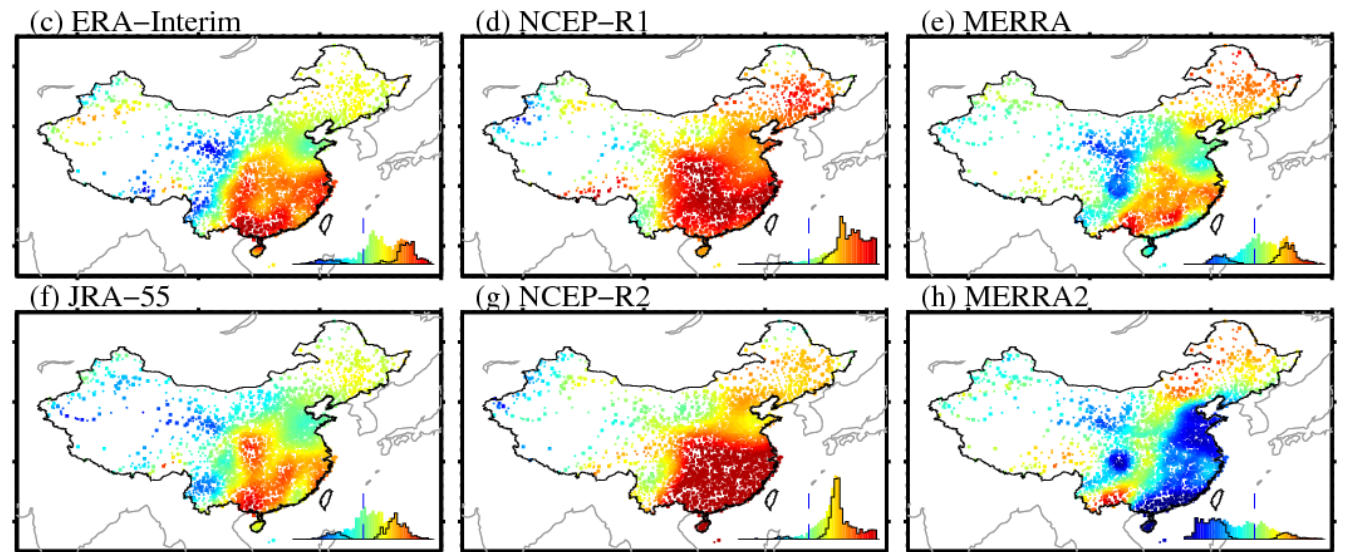

Climate reanalysis
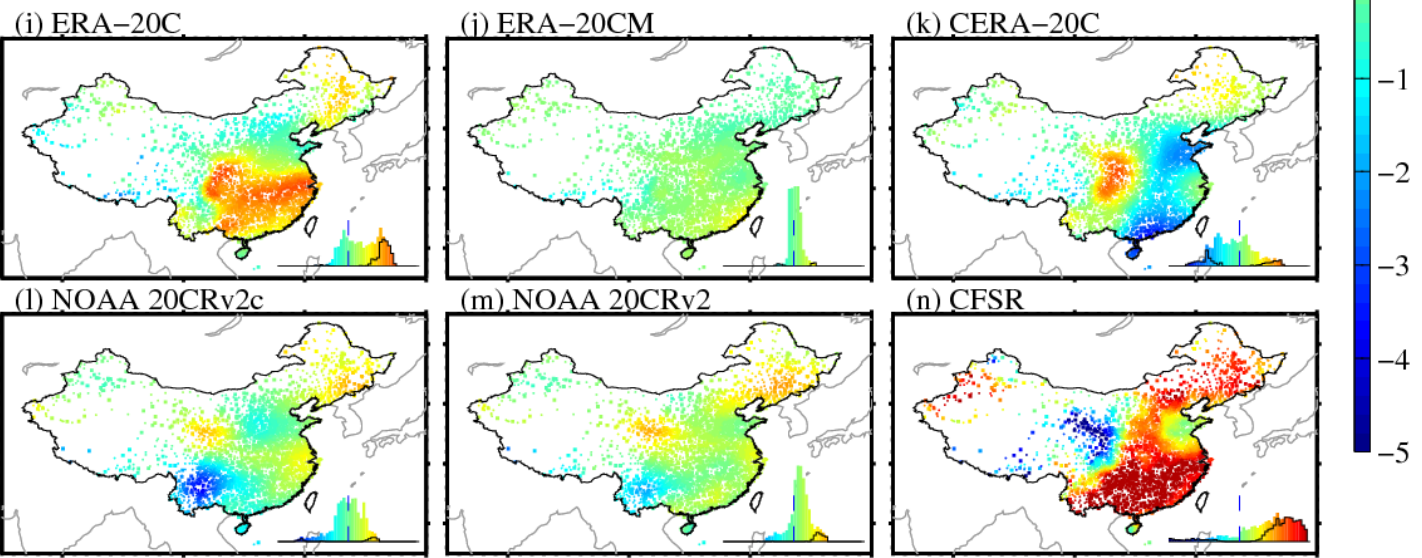

Figure S13. The trends in surface incident solar radiation $\left(R_{s}\right.$, unit: $\mathrm{W} \cdot \mathrm{m}^{-2} /$ decade $)$ during the period 1979-2010 from the observations and the twelve reanalysis products over China. The probability distribution functions of all the trends are shown as colored histogram, and the black stairs are integrated from the trends with a significance level of 0.05 (based on two-tailed Student's $t$-test). 

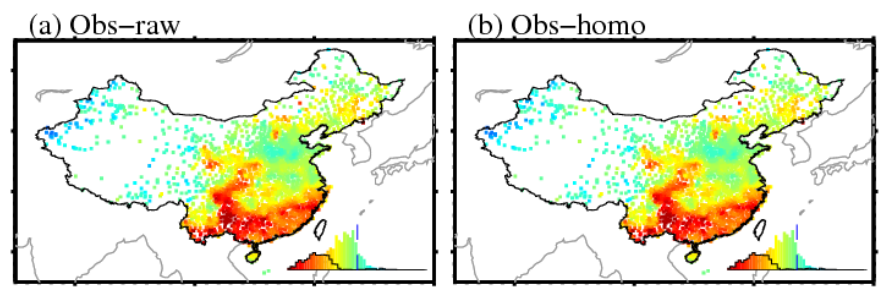

NWP reanalysis
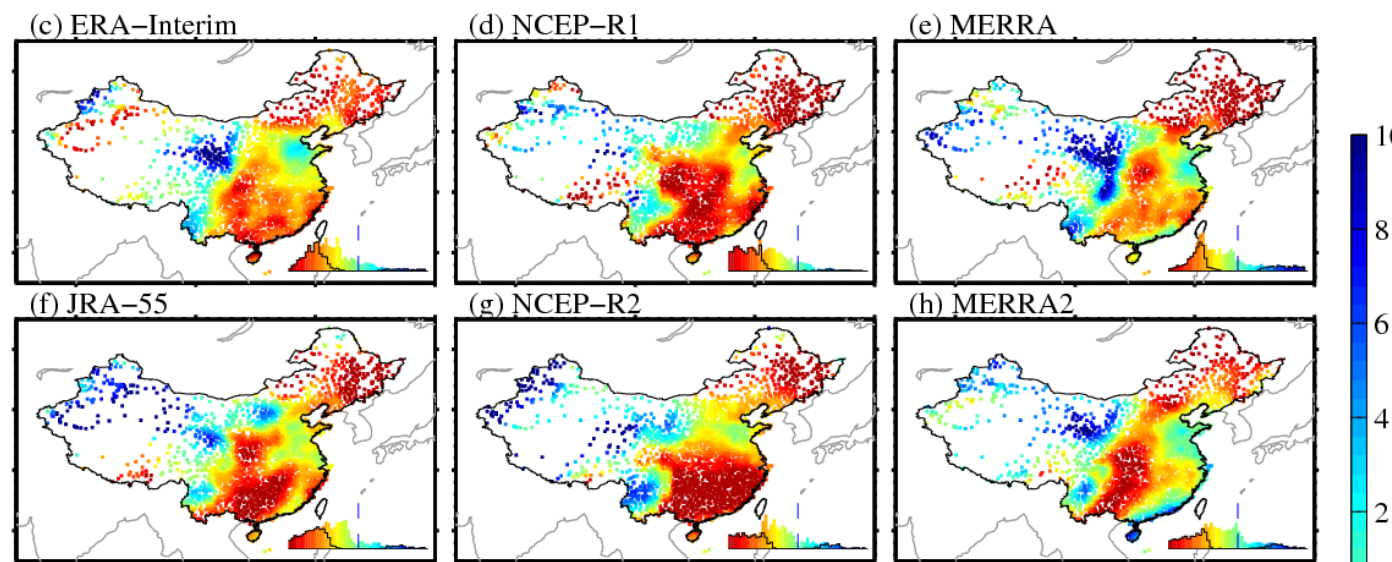

\section{Climate reanalysis}
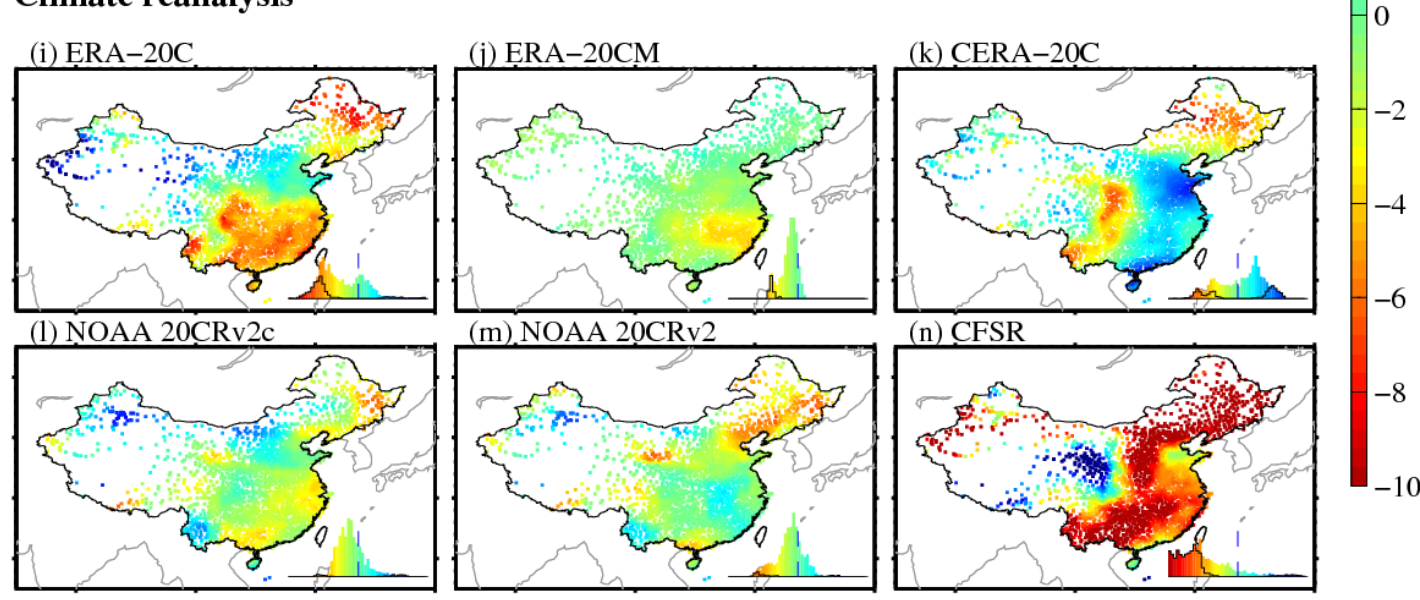

Figure S14. The trends in precipitation frequency (unit: days/decade) during the period 1979-2010 from the observations and the twelve reanalysis products over China. The probability distribution functions of all the trends are shown as colored histogram, and the black stairs are integrated from the trends with a significance level of 0.05 (based on two-tailed Student's $t$-test). 

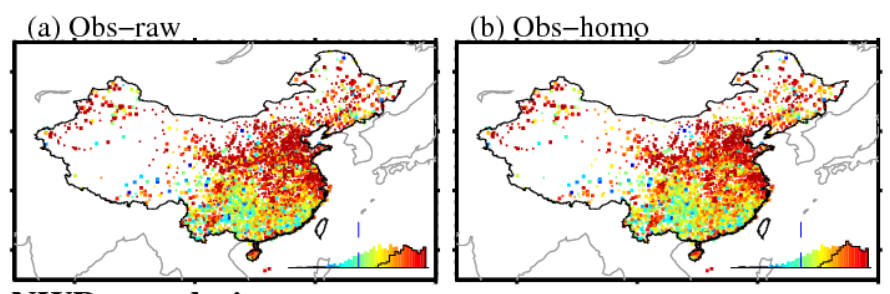

\section{NWP reanalysis}
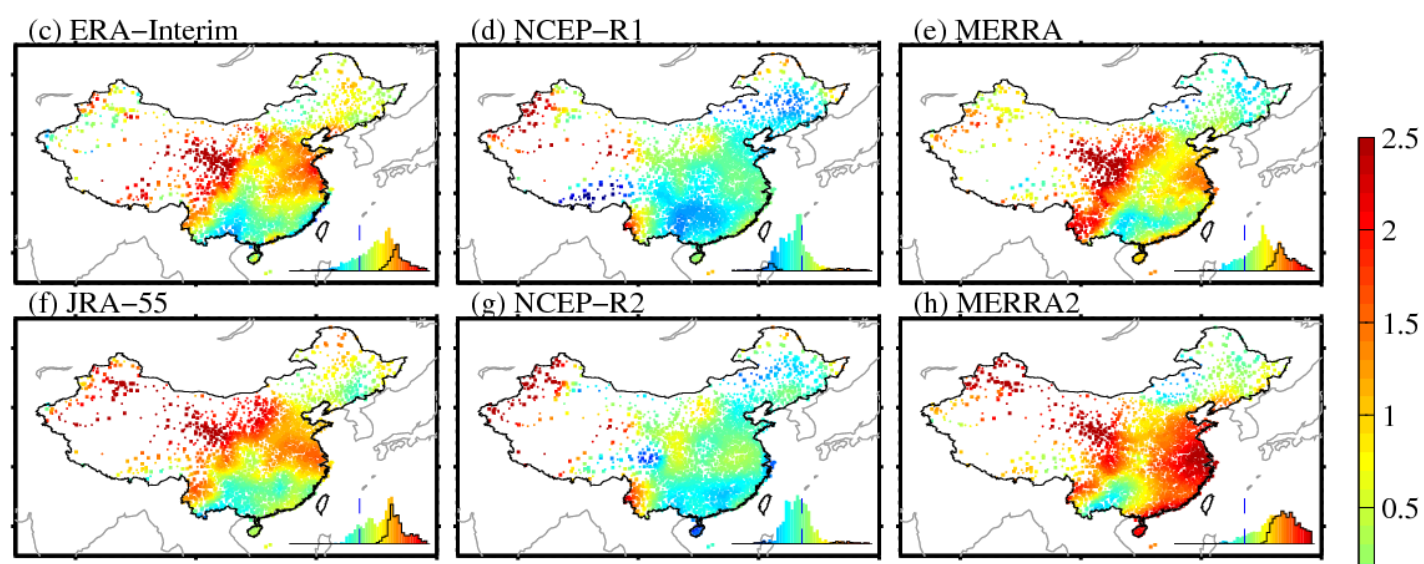

\section{Climate reanalysis}
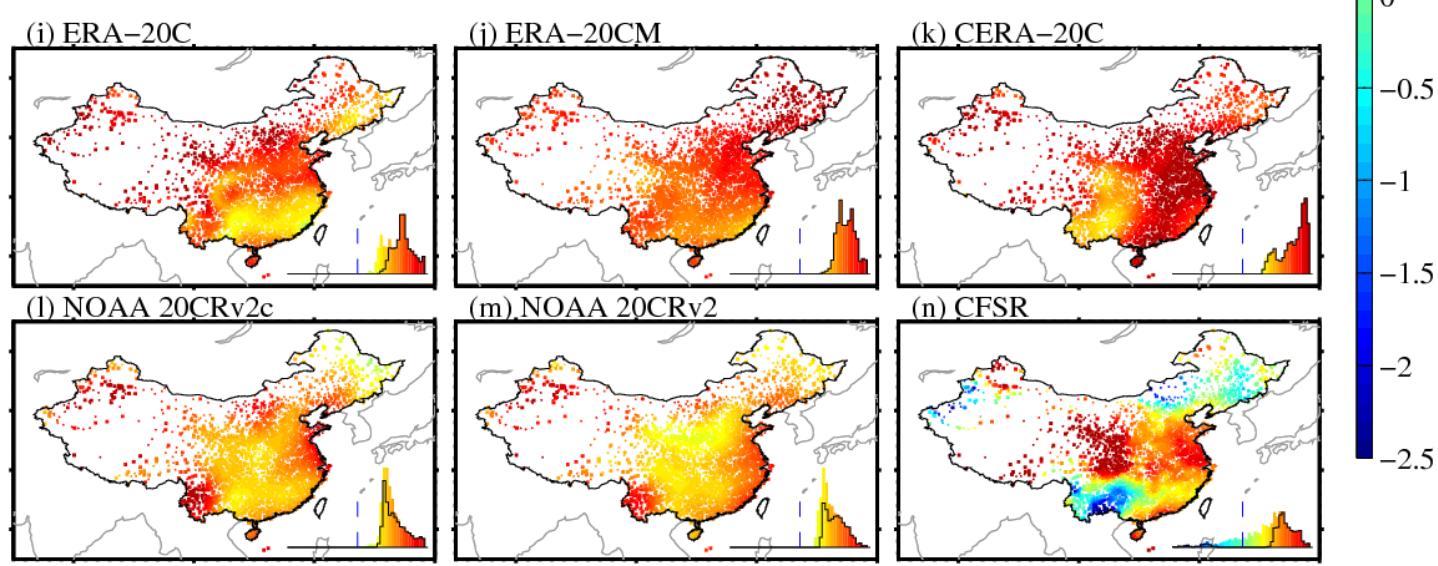

Figure S15. The trends in surface downward longwave radiation ( $L_{d}$, unit:

$\mathrm{W} \cdot \mathrm{m}^{-2} /$ decade) during the period 1979-2010 from the observations and the twelve with a significance level of 0.05 (based on two-tailed Student's $t$-test). 

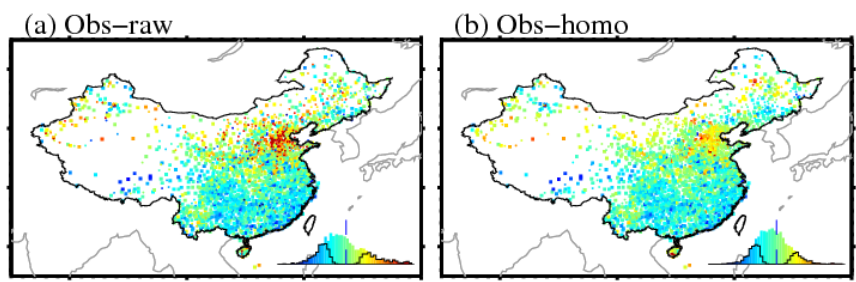

\section{NWP reanalysis}
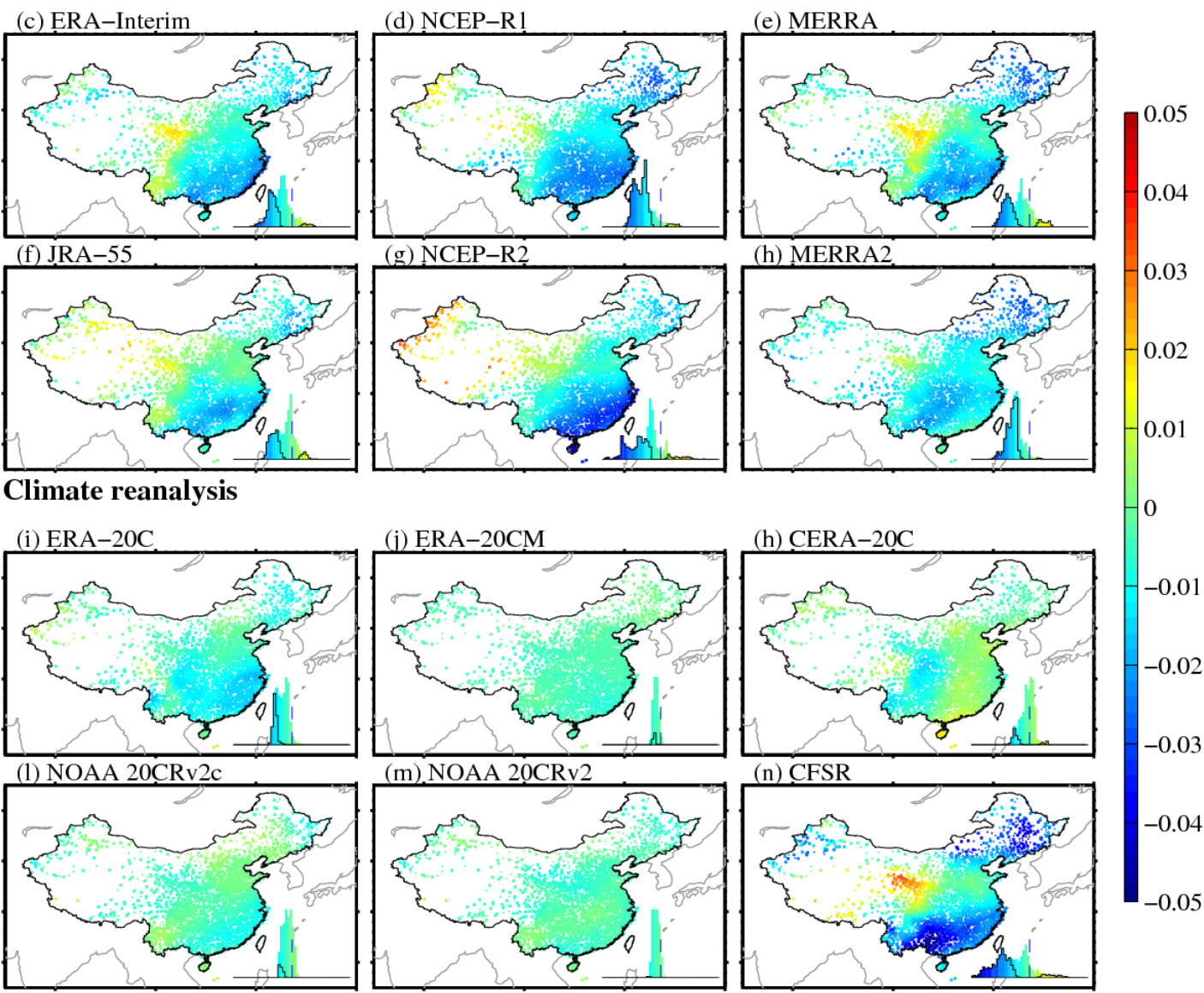

Figure S16. The trends in cloud fraction (cld, unit: 1/decade) during the period 1979-2010 from the observations and the twelve reanalysis products over China. The probability distribution functions of all the trends are shown as colored histogram, and the black stairs are integrated from the trends with a significance level of 0.05 (based on two-tailed Student's $t$-test). 

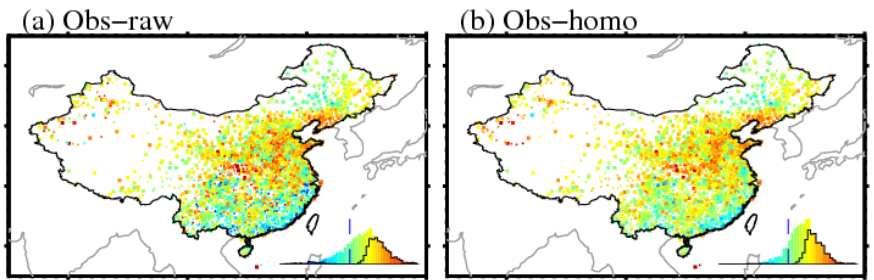

\section{NWP reanalysis}
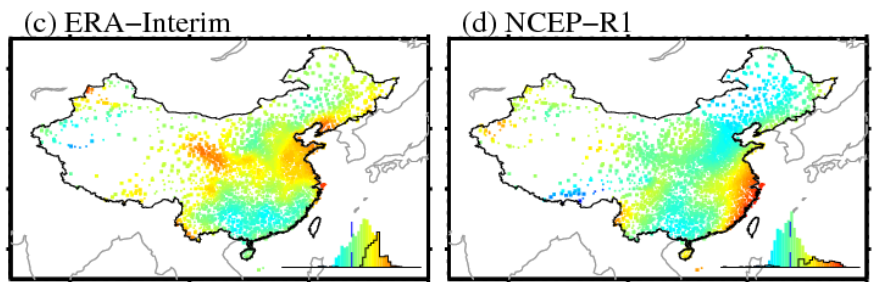

(e) MERRA
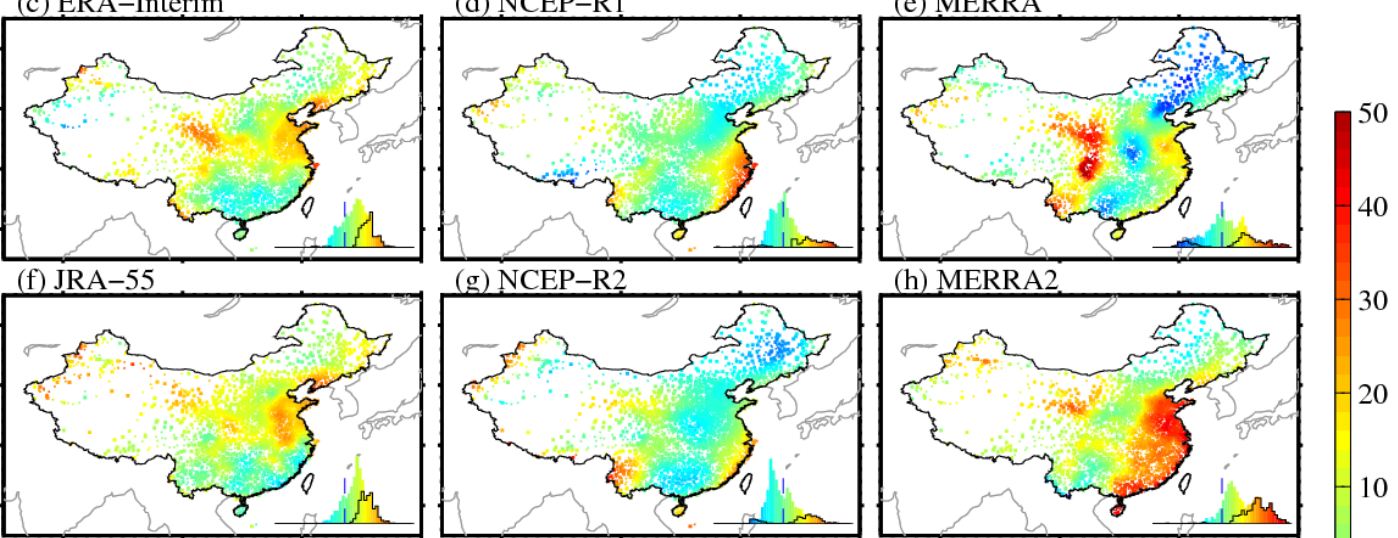

\section{Climate reanalysis}
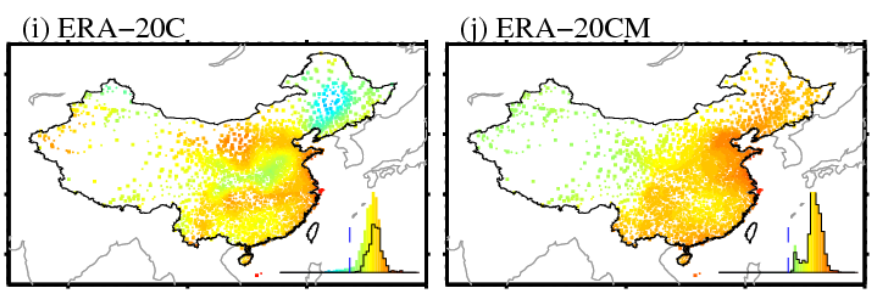

(h) CERA-20C
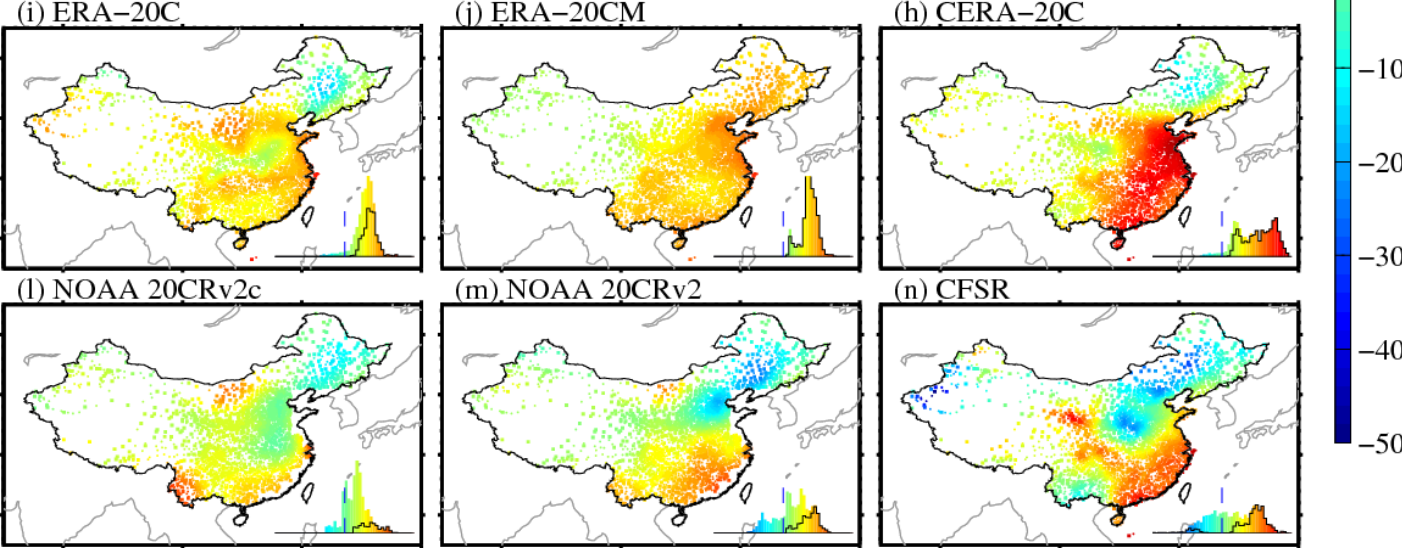

Figure S17. The trends in the atmospheric water vapor (WVP, unit: Pa/decade) during

the period 1979-2010 from the observations and the twelve reanalysis products over

China. The probability distribution functions of all the trends are shown as colored

histogram, and the black stairs are integrated from the trends with a significance level of 0.05 (based on two-tailed Student's $t$-test). 


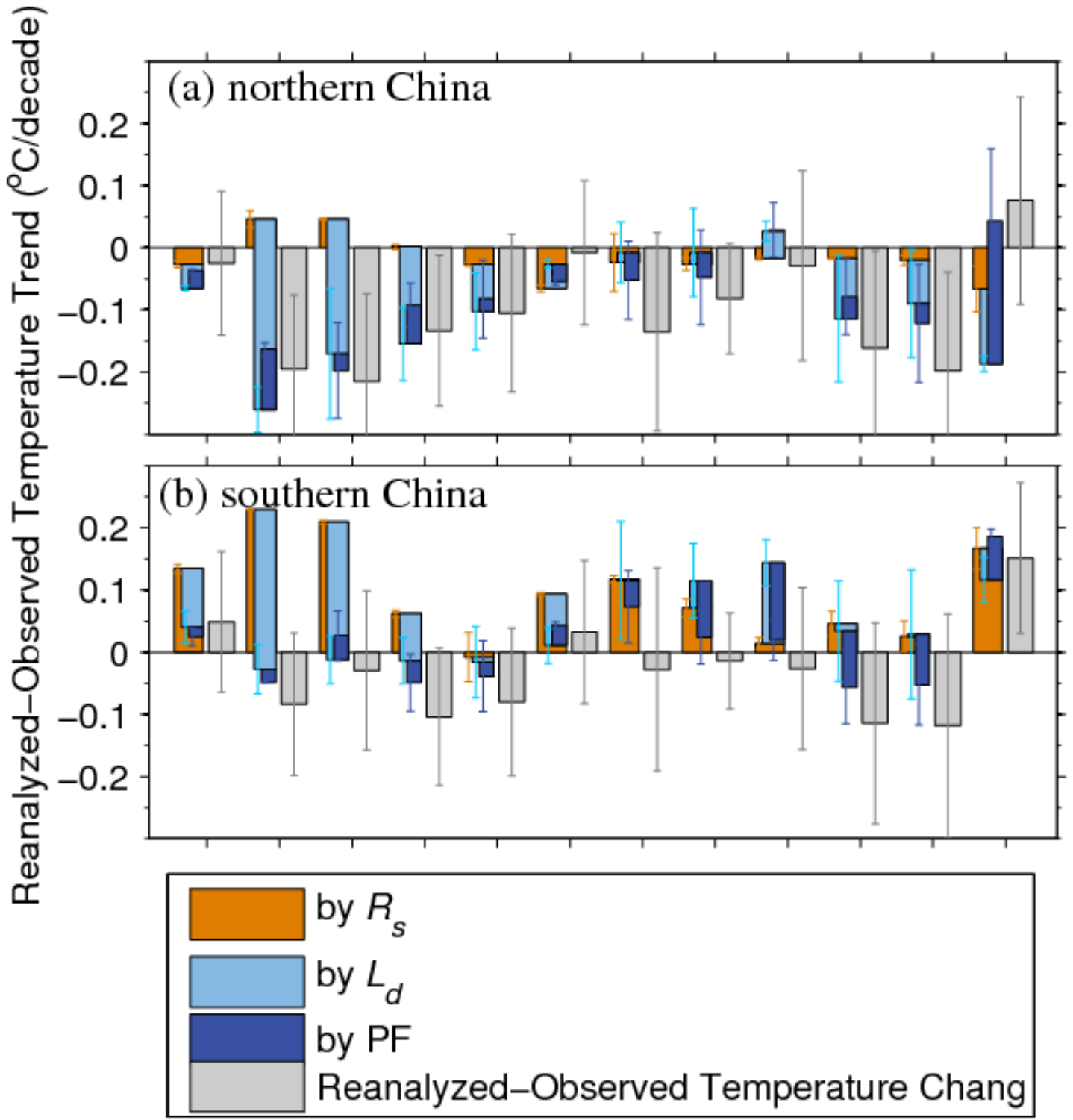

122 Figure S18. The same as Figure 7, but over northern China (including the Tibetan

123 Plateau, Northwest China, Loess Plateau, Northeast China) and southern China 124 (including the North China Plain, Middle China and Southeast China). 


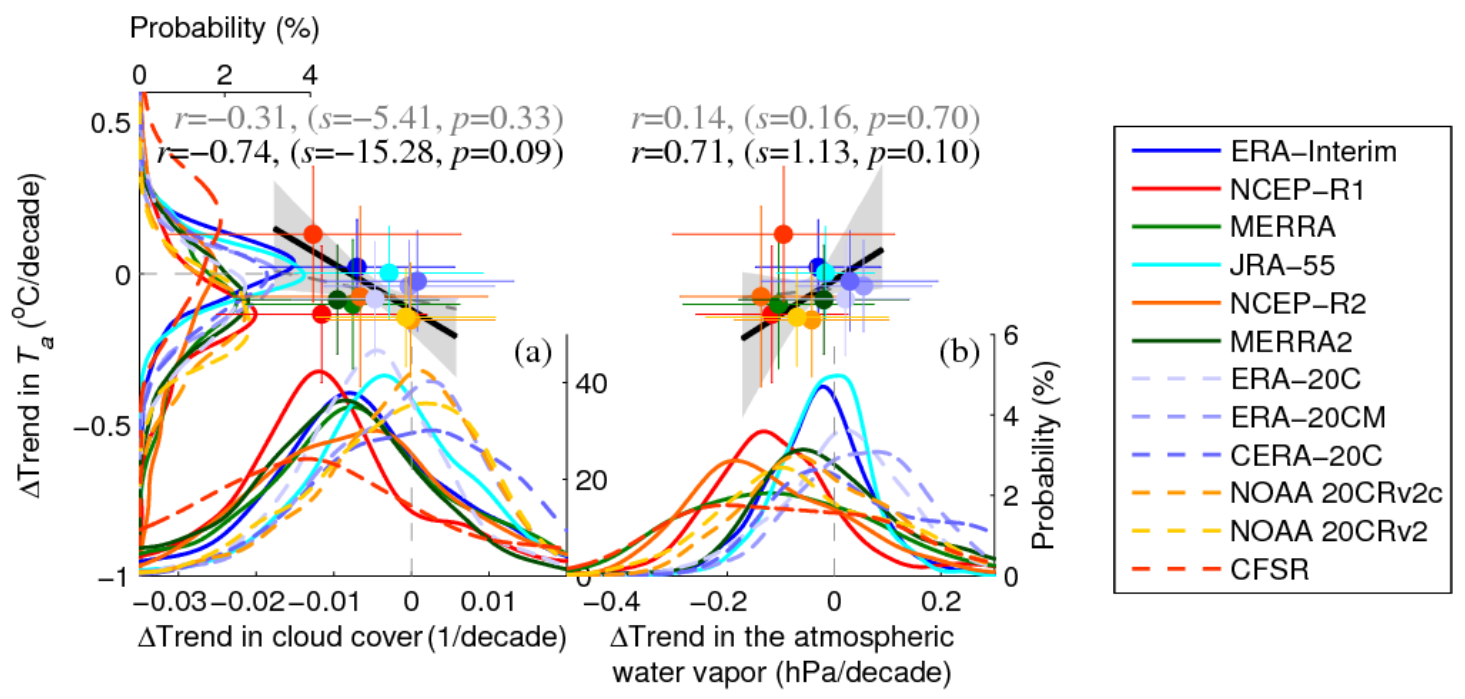

Figure S19. The same as Figure 8, but for the simulated biases in (a) cloud fraction and (b) the atmospheric water vapor. 


\section{(a) Tibetan Plateau}

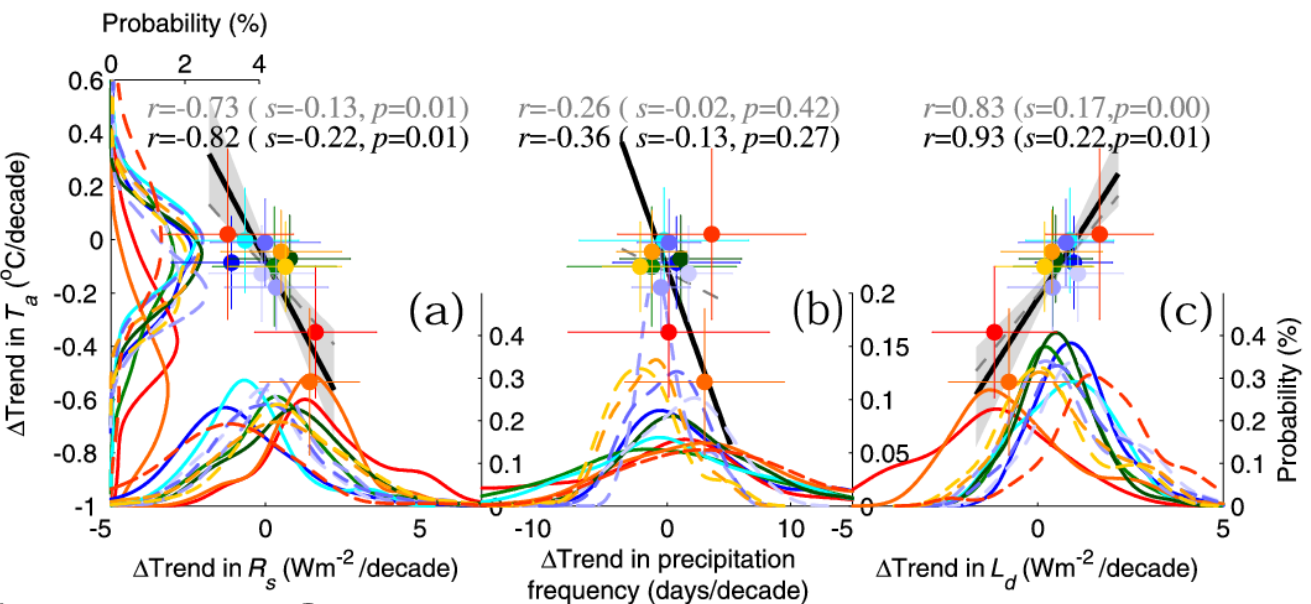

\section{(b) Northwest China}

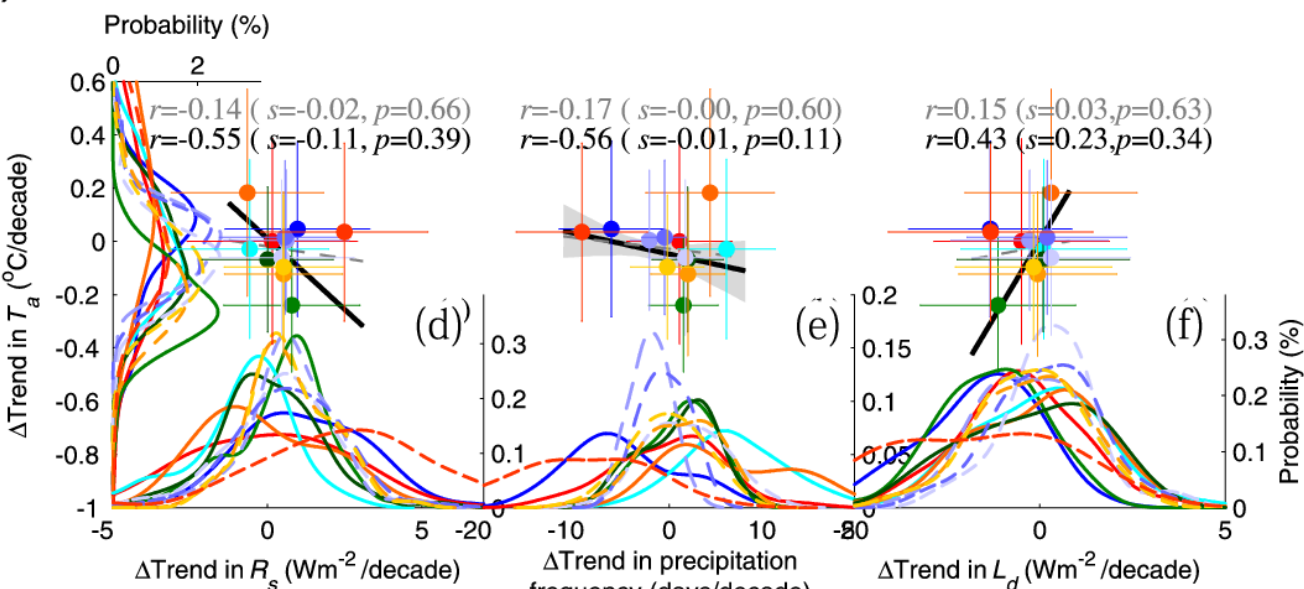

(c) Loess Plateau

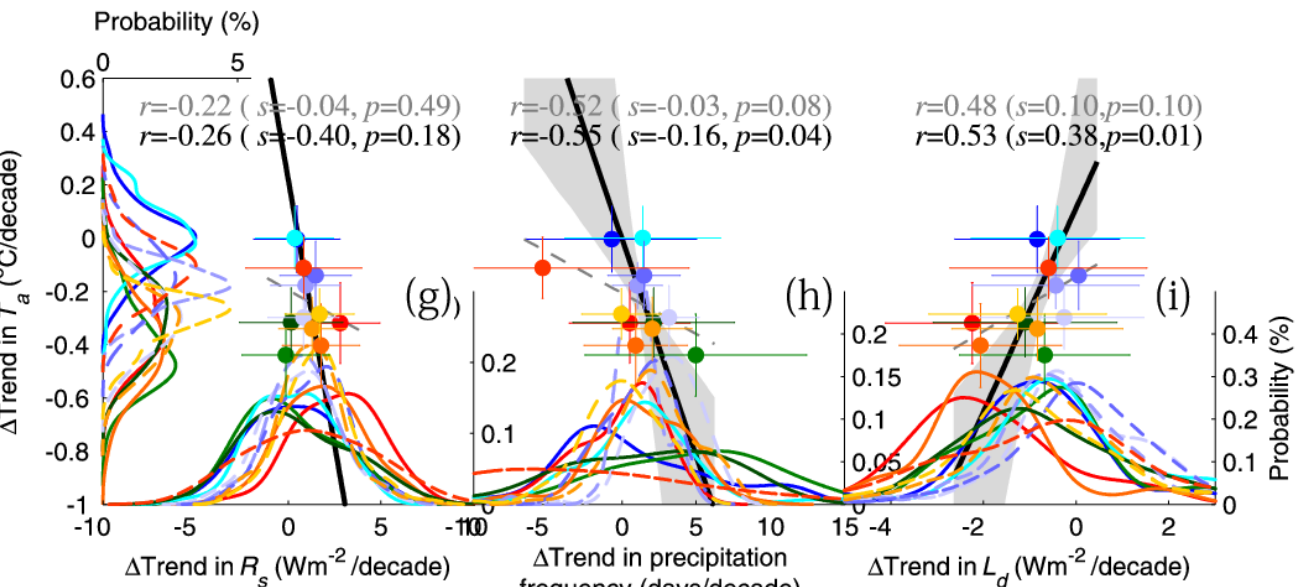

\section{(d) Middle China}

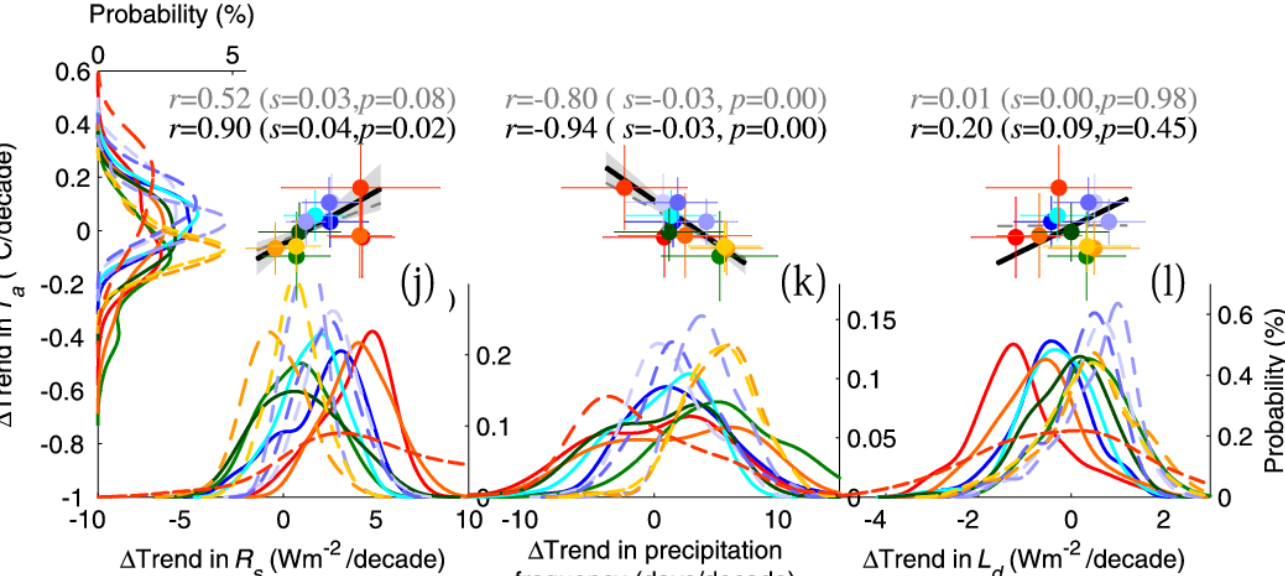

(e) Northeast China

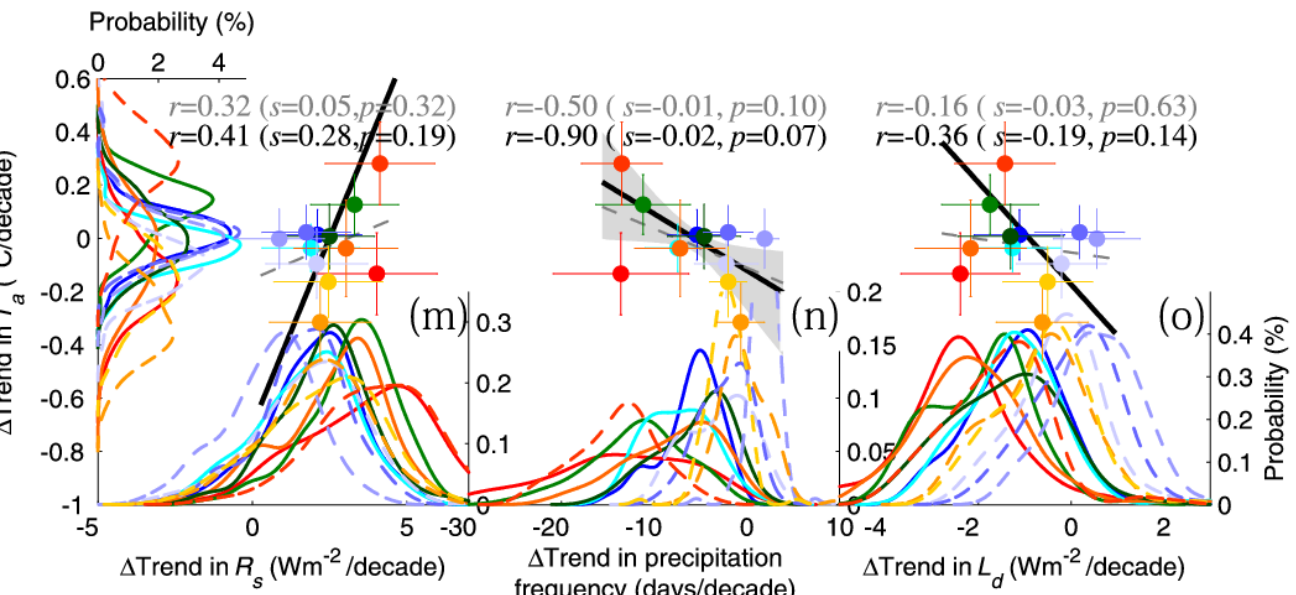

\section{(f) North China Plain}

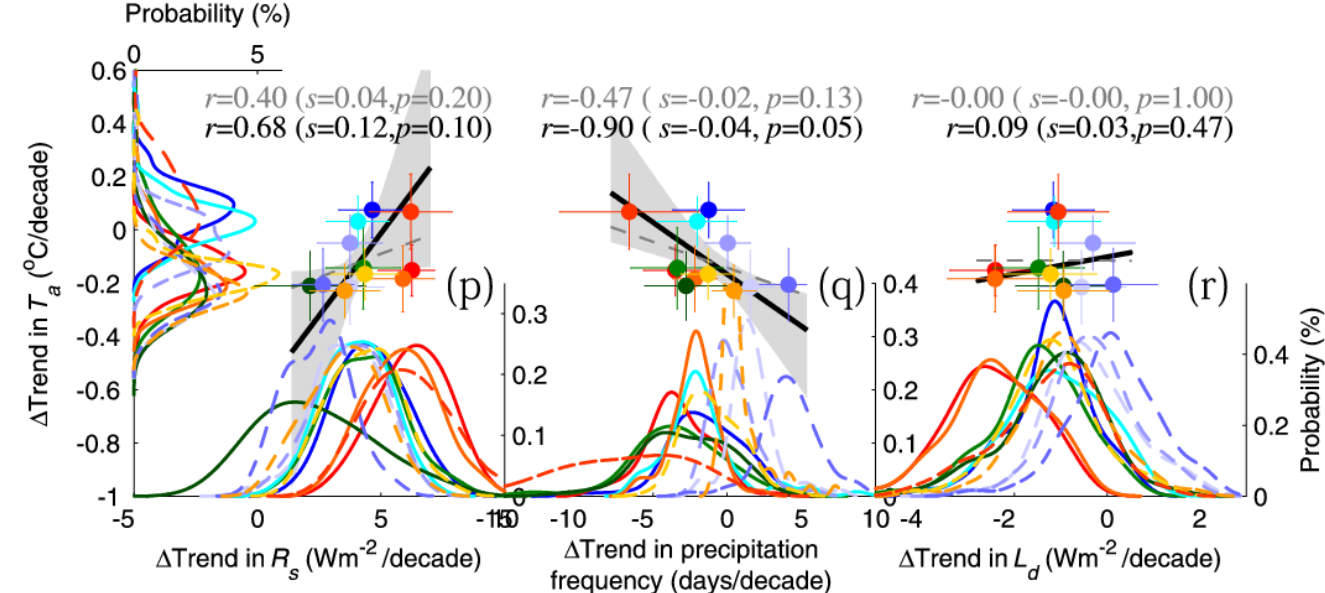

(g) Southeast China

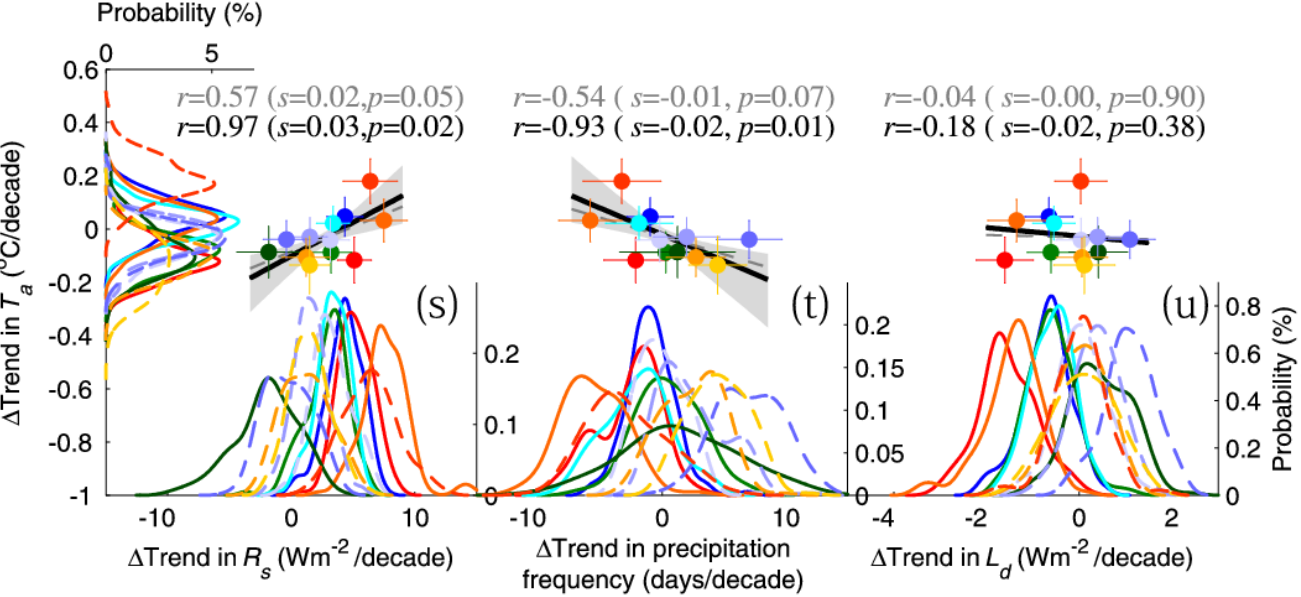

129 Figure S20. The same as Figure 8, but over China's subregions. 


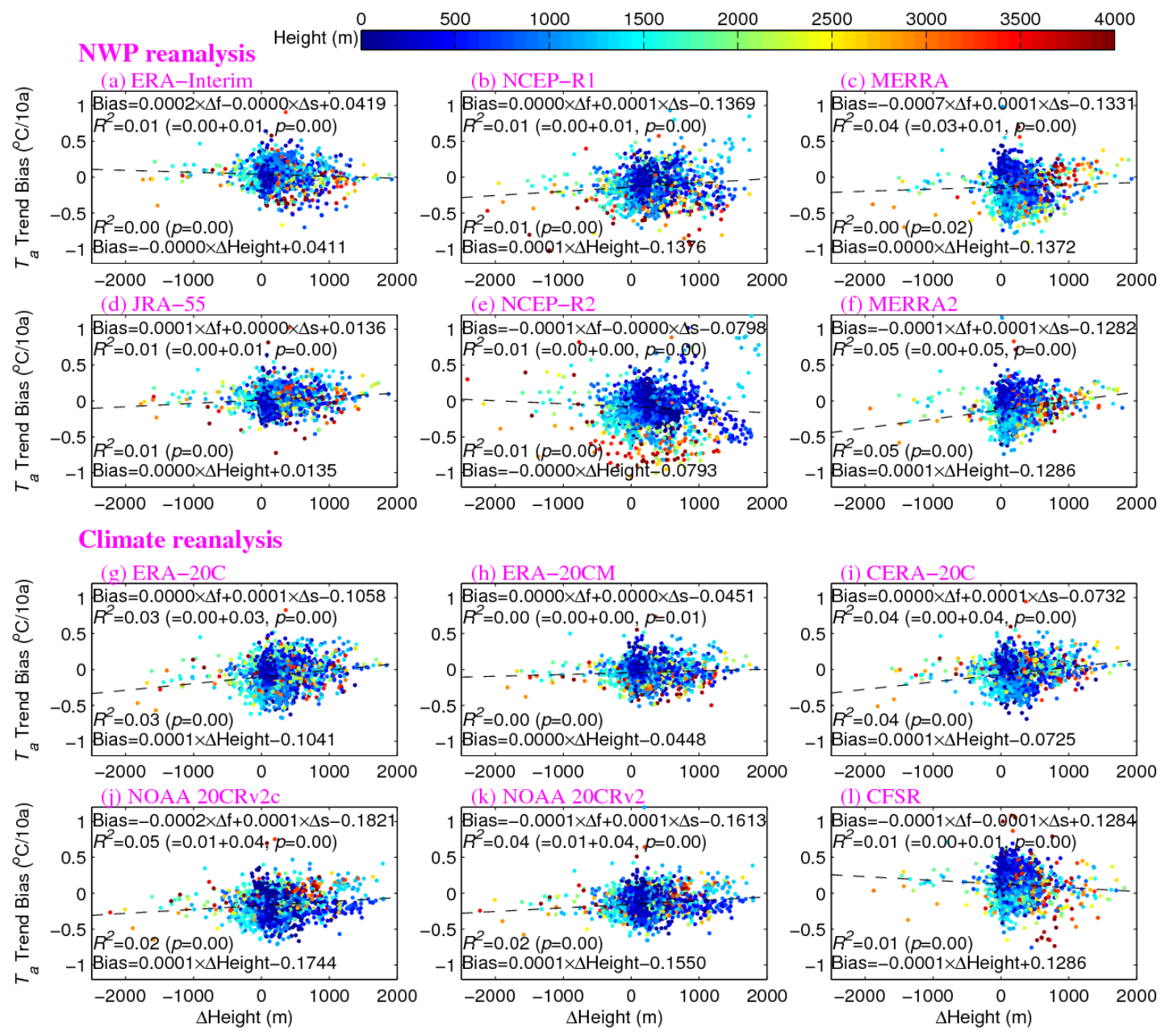

Figure S21. The same as Figure 2, but for the trend biases in surface air temperature

132 ( $T_{a}$, unit: $\left.{ }^{\circ} \mathrm{C} / \mathrm{decade}\right)$. The elevation difference between model and stations actually

133 influence the trend bias in $T_{a}$, but can not explain the spatial pattern in the trend bias

134 in $T_{a}\left(R^{2}=0.02\right)$, mainly due to the nearest warming within the lowest atmospheric

135 boundary layer. Moreover, compared the same-grid models (NOAA 20CRv2c vs.

136 NOAA 20CRv2, MERRA vs. MERRA2, NCEP-R1 vs. NCEP-R2 and ERA-20C vs.

137 ERA-20CM), we found the one statistically correlates with the elevation difference

138 but the other does not, which implies that this statistical correlation should not be

139 physical significance. Additionally, the elevation difference does not change with

time. 


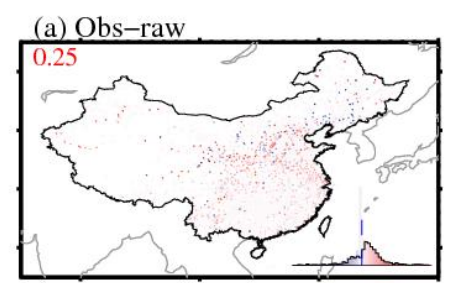

NWP reanalysis
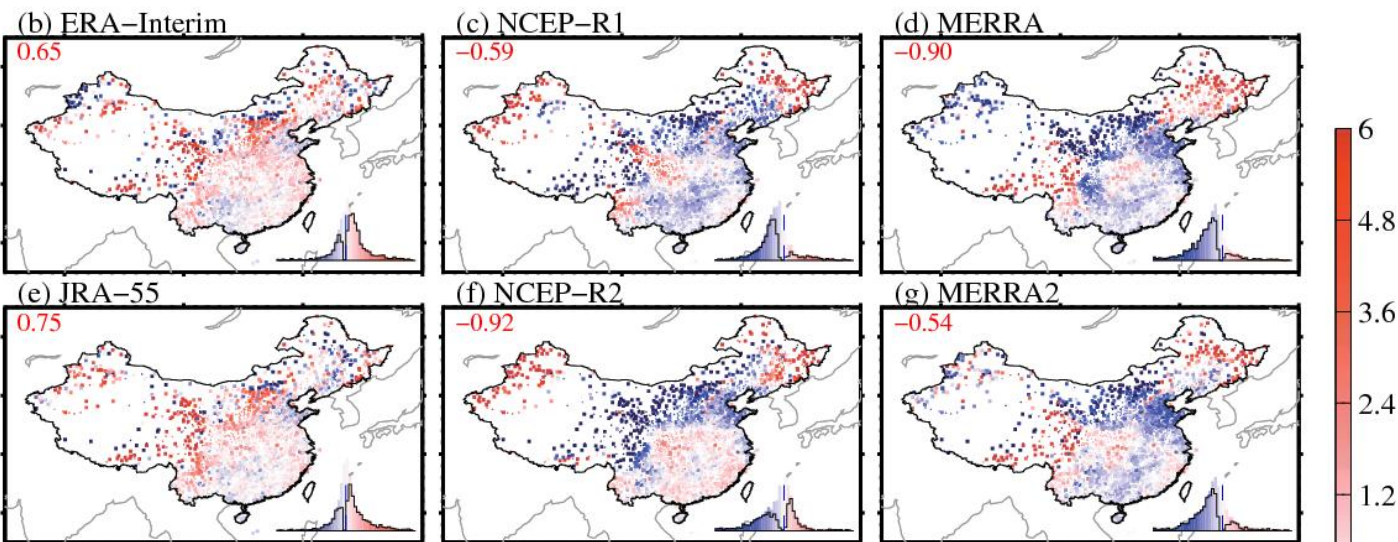

3.6

2.4

1.2

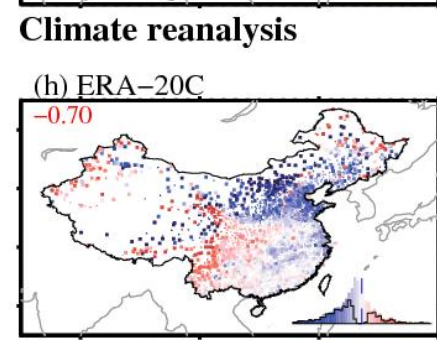

(k) NOAA 20CRv2c

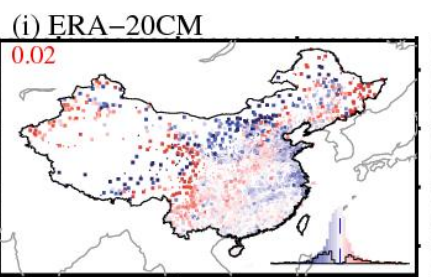

(i) CERA-20C
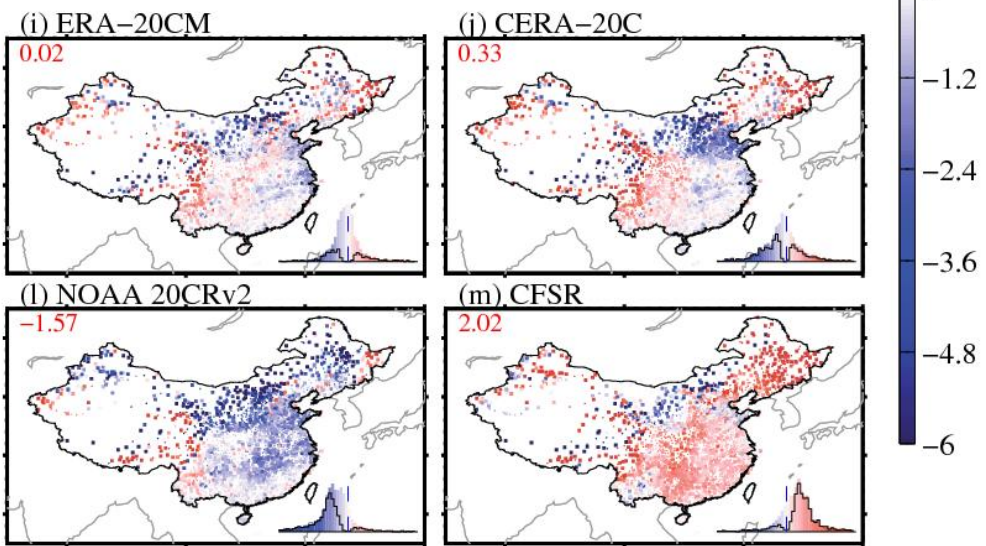

Figure S22. The same as Figure 5, but for the normalized trends in surface air

143 temperature (\%/decade). The normalized trends can exclude the impact of absolute

144 value of temperature on the trends. One can find that the spatial patterns in the

145 normalized trends is very near to those of the trends, implying the impact of

146 difference in absolute value of temperature due to the site-to-grid inconsistency can be

147 neglected. This result is consistent with that based on Figure S20. 


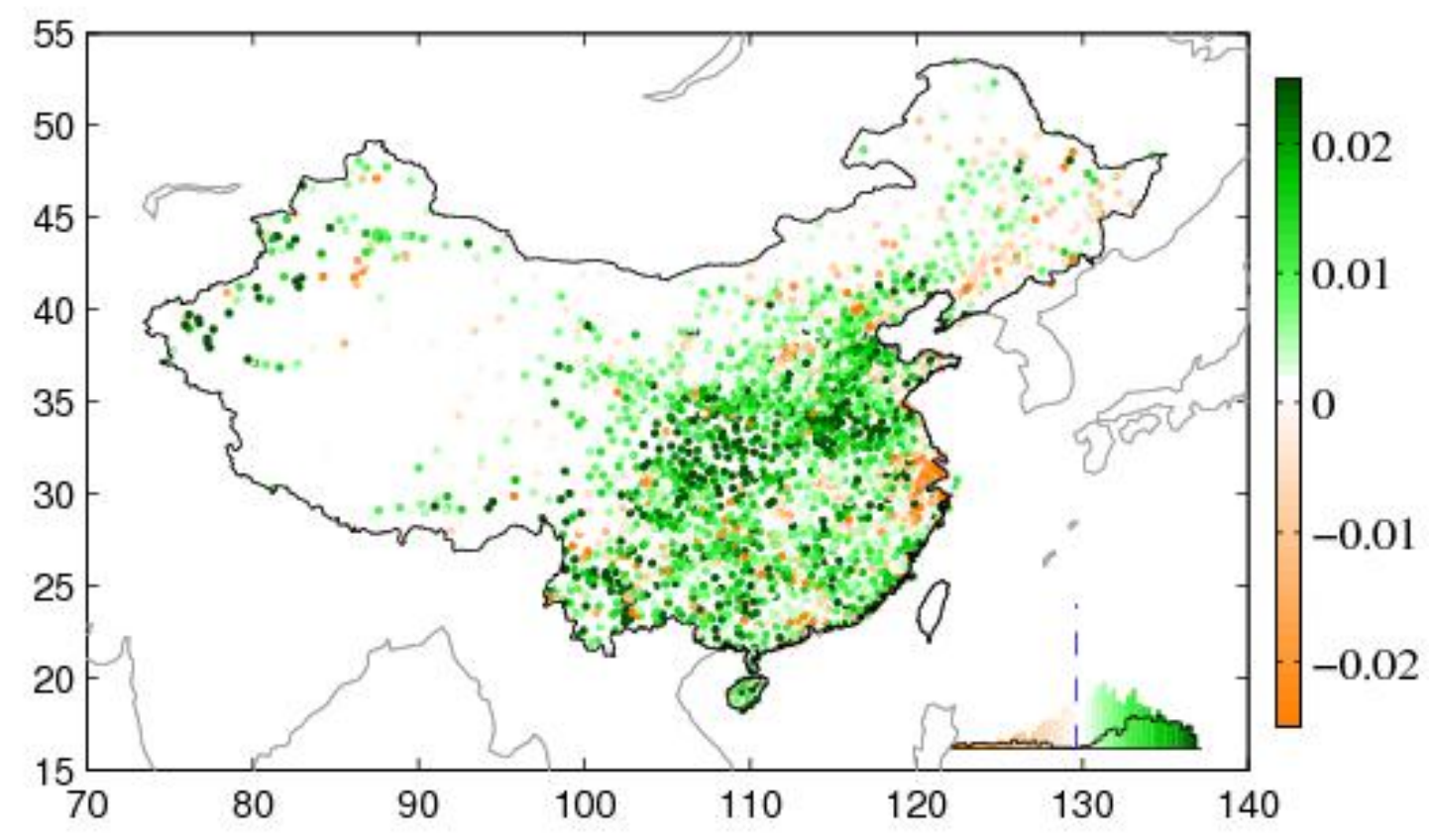

149 Figure S23. The trend in vegetation growth depicted by Normalized Difference

150 Vegetation Index (NDVI, unit: 1/decade) during the period 1981-2010 from the 151 observations and the twelve reanalysis products over China. The probability

152 distribution functions of all the trends are shown as colored histogram, and the black 153 stairs are integrated from the trends with a significance level of 0.05 (based on 154 two-tailed Student's $t$-test). 